\title{
Recent research on geometry education: an ICME-13 survey team report
}

\author{
Nathalie Sinclair $^{1} \cdot$ Maria G. Bartolini Bussi $^{2} \cdot$ Michael de Villiers $^{3} \cdot$ Keith Jones $^{4} \cdot$ Ulrich \\ Kortenkamp $^{5} \cdot$ Allen Leung $^{6} \cdot$ Kay Owens $^{7}$
}

\begin{abstract}
This survey on the theme of Geometry Education (including new technologies) focuses chiefly on the time span since 2008. Based on our review of the research literature published during this time span (in refereed journal articles, conference proceedings and edited books), we have jointly identified seven major threads of contributions that span from the early years of learning (pre-school and primary school) through to post-compulsory education and to the issue of mathematics teacher education for geometry. These threads are as follows: developments and trends in the use of theories; advances in the understanding of visuo spatial reasoning; the use and role of diagrams and gestures; advances in the understanding of the role of digital technologies; advances in the understanding of the teaching and learning of definitions; advances in the understanding of the teaching and learning of the proving process; and, moving beyond traditional Euclidean approaches. Within each theme, we identify relevant research and also offer commentary on future directions.
\end{abstract}

Keywords Geometry $\cdot$ Technology $\cdot$ Diagrams $\cdot$ Definitions $\cdot$ Gestures $\cdot$ Proving $\cdot$ Digital technology $\cdot$ Visuospatial reasoning

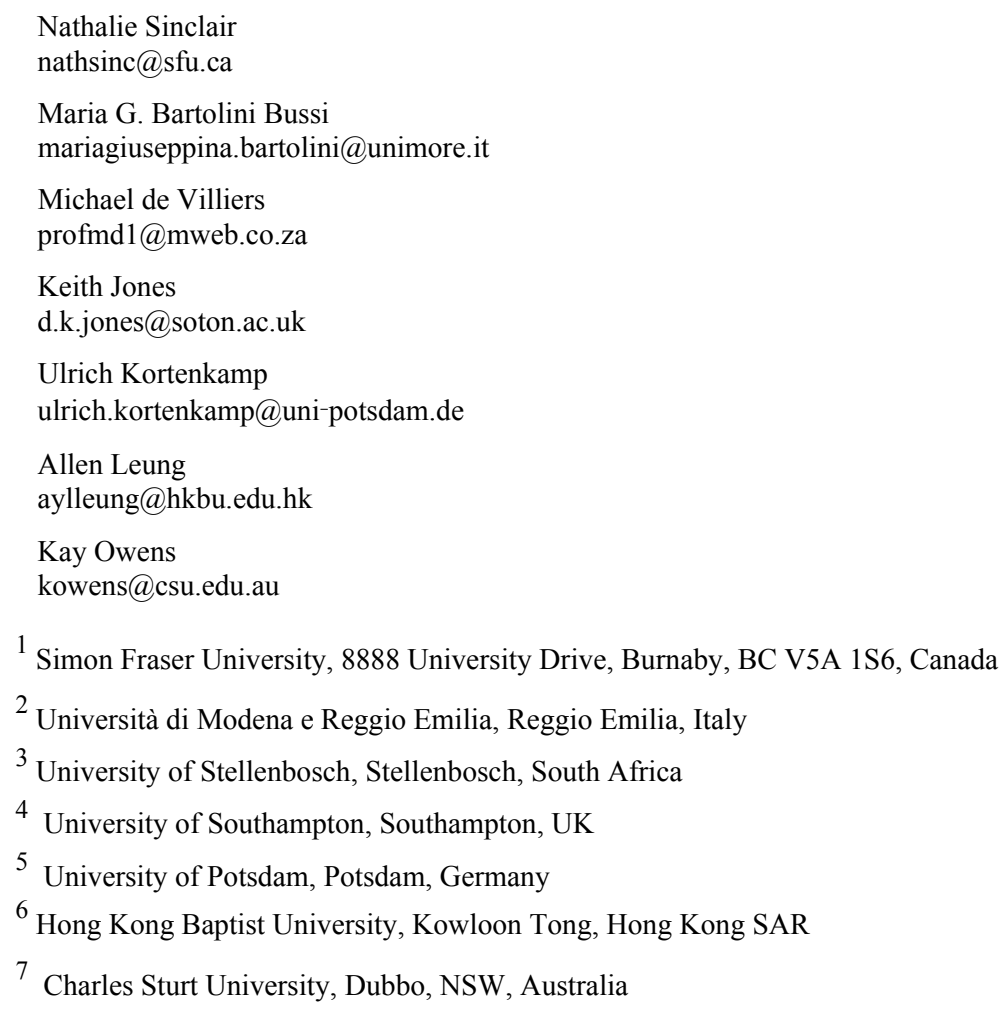

\section{Introduction}

This survey on the theme of Geometry Education (including new technologies) focuses chiefly on the time span since 2008. As stipulated in the Survey Team procedure, our first task, as a team, was to identify major threads of contribution to our theme. We undertook this phase of work by generating a list of threads, based on our collective knowledge and experience, which represented the most important developments and contributions during our target time period. Each team member proposed a list of topics that could be considered for the threads. Some of these topics were combined, so as to produce a broader thread. Some were rejected if it was decided that there was not sufficient research literature on which to draw. This iterative process of combining topics led to the articulation of seven distinct threads, each of which were assigned to two 
members of the survey team. The seven threads are as following: developments and trends in the use of theories, advances in the understanding of visuo-spatial reasoning, the use and role of diagrams and gestures, advances in the understanding of the role of technologies, advances in the understanding of the teaching and learning of definitions, advances in the understanding of the teaching and learning of the proving process and moving beyond traditional Euclidean approaches.

In the next phase of work, the pairs of survey team members identified literature relevant to their threads by consulting peer-reviewed journal articles published since 2008, as well as international peer-reviewed conference proceedings such as PME and CERME. Since two of the members of the team (Sinclair and de Villiers) had also co-authored a forthcoming handbook chapter (the NCTM Compendium) on geometry, some of this literature had already been identified. Other handbook chapters focused on geometry that the team reviewed were all published prior to 2008. For each thread, we produced an annotated bibliography that was shared across the team in an effort to identify lacuna and overlaps, which led to a further refinement of the threads. Following this, each pair of team members produced a written overview of the research related to their respective threads. These overviews were then combined and again reviewed in order to minimise over-laps and create an optimal order of presentation. The next seven sections thus describe the research related to each major thread. We conclude with a final section in which we highlight some overall issues and opportunities and discuss future directions for research.

\section{Developments and trends in the use of theories}

The development and refinement of theories of teaching and learning is one of the key aims of research in education. This focus on theory includes the developing and refining of theories that are specifically about the teaching and learning of geometry, as well as the application of more general theories to the specifics of geometry education.

Examples of theories specifically about the teaching and learning of geometry include the van Hiele model of geometrical thinking (van Hiele 1986), the theory of figural concepts (Fischbein 1993, Mariotti \& Fischbein 1997), the theory of figural apprehension (Duval 1998), and the theory of geometric work (c.f., Kuzniak 2014). Examples of more general theories applied to the specifics of geometry education include the use of prototype phenomenon (c.f., Hershkowitz 1990), semiotic bundle (c.f., Arzarello, 2006) and semiotic mediation (Bartolini Bussi \& Mariotti 2008), the theory of variation (c.f., Gu, Huang \& Marton 2004), the cK $\varnothing$ (conception, knowing, concept) model (c.f., Balacheff \& Margolinas 2005; Balacheff 2013), as well as more recent use of discursive, embodied, ecocultural and material perspectives (c.f., Ng \& Sinclair 2015a, b; Owens 2014, 2015). The use of the framework of instrumental genesis (Verillon \& Rabardel 1995) is evident in research on the use of digital technologies for geometry education (e.g., Hegedus \& Moreno-Armella 2010).

\subsection{Theories specifically about the teaching and learning of geometry}

After reviewing research on each of the examples of theories specifically about the teaching and learning of geometry listed above, we provide a commentary that aims to draw links between such research.

\subsubsection{The van Hiele model of geometrical thinking}

The van Hiele model originated in the 1950s (1986) and posits that learners make progress through as many as five 'levels' of thought in geometry. After a flurry of attention in the 1970s and 1980s, research began to indicate that the levels may not be as discrete as might be envisaged by the model (c.f., Gutiérrez et al. 1991; Lehrer et al. 1998). In a similar vein, Wang and Kinzel (2014) analysed the "use of mathematical words and substantiation routines related to parallelograms and their properties" (p. 288) by trainee elementary school teachers and found that "a single van Hiele level of thinking encompasses a range of complexity of reasoning and differences in discourse" (ibid).

A recent use of the levels has been as a means of judging the general progression evident in curriculum material (such as textbooks). For example, in using the van Hiele levels in an analysis of the elementary and middle school (grades $\mathrm{K}$ to 8 ) State Standards in use in 42 States of the USA, Newton (2010), reported that the distribution of grade-level learning expectations (GLEs) was "consistent with the general thrust of the van Hiele theory, particularly the claim that the levels of geometric thinking are sequential” (p. 91). Forsythe (2015) studied students' dragging strategies in DGE and related different drag-modes in a geometrical task to the van Hiele levels.

While some researchers continue to find some utility in the van Hiele model of levels, a querying of the van Hiele model was made by Papademetri-Kachrimani (2012) who argued against the view that "geometrical thinking can be described through a hierarchical model formed by levels" (p. 2). She proffers a challenge to researchers to propose alternate models that move "away from the idea of levels" (p. 7). An example of this was explored by Owens and colleagues with categories of investigating and visualising, describing and classifying that were addressed at various times (Owens 2004, 2015).

While Watson et al. (2013, p. 98) note a general "lack of research on the five-phase (van Hiele) approach to teaching", Atebe and Schäfer (2011) developed and utilised a "checklist of van Hiele phase descriptors" (p. 194). Applying this check- 
list to videotaped recordings of six geometry lessons, three in Nigeria and three in South Africa, they reported that, "about $40 \%$ of the checklist criteria were satisfied by the lessons" (p. 202). They concluded that "learners whose instructional experiences are aligned most closely with the van Hiele phases of learning show a better understanding of geometric concepts than those whose experiences are not" (ibid). Further testing of this sort of approach would be valuable, as would further research on other aspects of the model of the five-phase approach to teaching geometry.

\subsubsection{The theory of figural concepts}

Fischbein (1993) proposed that a geometrical shape be considered as a figural concept of a dual symbiotic nature in that a shape simultaneously possesses figural properties and logical conceptual constraints. Later, the theory was applied to the issue of defining as an educational problem (Mariotti \& Fischbein 1997). In recent research, Erdogan and Dur (2014) investigated the relationships between pre-service mathematics teachers' personal figural concepts and quadrilateral hierarchical classifications. They found that these teachers' prototypical images learnt at school dominated in their personal figural concepts even though they possessed formal definitions of quadrilaterals. In a study by Walcott, Mohr and Kastberg (2009), students were asked about the similarities and differences between parallelogram and rectangle of equal area presented side by side on a grid. Two types of figural concept were identified: flexible prototype and inflexible prototype. Students possessing flexible prototype had dynamic figural concept that involved mentally manipulating the shapes.

\subsubsection{The theories of figural apprehension and dimensional deconstruction}

In Duval's (1998) notion of figural apprehension, there are four types of cognitive apprehension: perceptual apprehension (the initial apprehension of a geometrical figure); sequential apprehension (the appearance of sub-figures or elementary figural units); discursive apprehension (perceptual recognition associated with discursive statements accompanying a geometric figure); and operative apprehension (ways by which a given figure can be modified while retaining its geometric properties).

Gal and Linchevski (2010) utilised Duval's notion of figural apprehension in their work on student difficulties in geometry, in particular exemplifying "how processes which are prior to accompanying 'reasoning' influence the cognitive process" (p. 164). They found that it was difficult for students to distinguish within the configurations of a geometric diagram "the visual characteristics... that are relevant from those that are not" (p. 180). Such difficulties, they argue, emerge because students may not "go further from the first glance of a geometrical figure which is the result of visual perception" (ibid). Accordingly, they argue that visual perception is not only insufficient but "may even hinder the use and development of geometric concepts and properties" (ibid).

Because attending to the properties of a geometric figure involves dimensional deconstruction ('seeing' the properties of the rectangles involves attending to its sides and angles), Duval (2005), in more recent theoretical work, argues that school geometry proceeds in the wrong direction because it moves from solids to plane figures to lines. It assumes that students will be able to 'see' the 1D objects that determine the properties of the $2 \mathrm{D}$ shape. In order to support dimensional decomposition, Duval (2005) proposes construction as the point of entry: not just straightedge and compass constructions but also carpenter's squares, paper-folding, rulers and stencils - an approach that contrasts with van Hiele, for which undertaking construction by straight edge and compass is Level 3. In the course of constructing a shape, the dimensional decomposition is done by the geometric tools (straight-edge decomposes the 2D square in a 1D line). Drawing on Duval's work, Perrin-Glorian, Mathé \& Leclerc (2013) argue that instruments such as rulers and stencils could play an important role in enabling dimensional deconstruction. They propose a series of 'restoration' tasks in which tool-based construction is used to explore reflectional symmetry beginning in kindergarten and progressing throughout the grades. For example, children are asked to use tools to complete the outline of a symmetric tree that has been partially erased, but that is the dilation and rotation of another intact tree.

\subsubsection{The theory of spaces for geometric work}

The framework of Spaces for Geometric Work (SGW), as Gómez-Chacón and Kuzniak (2015) explain, describes "the work that people (students, teachers, mathematicians, etc.) perform when they solve geometric tasks" (p. 202). According to the SGW theory (see also Kuzniak 2014), there are two interconnected 'planes': the epistemological and the cognitive. In the epistemological plane, there are three intersecting elements: material support, artefacts, and a frame of reference based on geometric definitions and properties. The cognitive plane comprises the three cognitive processes of Duval (2005): a visualisation process, a construction process determined by instruments (ruler, compass, etc.) and geometrical configurations; and a dis-cursive process that conveys geometric argumentation and proofs. 
The research reported by Gómez-Chacón and Kuzniak (2015) focused on the effect of DGEs on "relationships between the three geneses (figural, instrumental, and discursive) of Spaces for Geometric Work" (p. 201). In their study, 98 trainee teachers tackled a geometry task in one session, and then worked on an extension to the problem in a second session. The authors found evidence of "two main forms of SGW" (p. 222); one that focused "mainly on a discursive genesis of proof supported by an analytic visual work on the figure with no specific attention paid to drawing tools" (ibid) and a second where the trainee teachers "identified the properties of symmetry and invariance of angles and were guided by perception and visualisation of the figure as well as by use of instruments" (p. 223).

This exemplifies how the epistemological dimension and the cognitive dimension of SGW can serve as a frame to study different types of geometrical reasoning with respect to the degree of mixture between the two dimensions.

\subsubsection{Commentary on specific theories used in geometry education research}

Two trends can be discerned in recent van Hiele-based research. One trend is that some researchers-albeit small in number - are still finding the idea of learners making progress through 'levels' of thought in geometry to be useful. The alternative trend is to relate the van Hiele levels to different types of geometrical reasoning under a pedagogical environment. The levels may not be hierarchically arranged but related by students' pedagogical discourses and activities.

Studies of the transition between types of figural concept indicate that this is not automatic. A major issue is the difficulty to interpret the sensory/cognitive dichotomy. It may be constructive to study how Duval's four cognitive apprehensions can pedagogically complement each other in the transition phases and instead of sensory/cognitive dichotomy, it may be that sensory-cognitive unity is a more insightful stance. Duval's focus on tool-based dimensional deconstruction, and on the visualisation, construction and discursive processes, may serve as a useful frame to design meaningful mathematical tasks.

\subsection{General theories applied to the specifics of geometry education}

While, in what follows, research is reviewed that has utilised the general theories listed in the introduction to this section, we do not include the theory of semiotic mediation (covered in Sect. 3) nor theories drawing on embodied cog-nition (discussed in Sect. 3). The use of the framework of instrumental genesis is mentioned in Sect. 5.

\subsubsection{Prototype theory}

Prototype theory originated in cognitive science in the 1960s as a way of explaining why some members of a cate-gory are more central than others; in education the idea has been used in research on concepts and conceptual development. One theme in geometry education where this has been applied is the classification of geometric shapes (c.f., Hershkowitz 1990). This prototype phenomenon has been, and continues to be, the subject of research. Fujita (2012), for example, investigated learners' understanding of inclusion relations of quadrilaterals by proposing a theoretical model and method (Q-Level) to describe learners' cognitive development of such relations. The findings suggested that in general more than half of aboveaverage learners are likely to recognise quadrilaterals primarily by prototypical examples, even though they know the correct definition, and this causes them difficulty in understanding the inclusion relations of quadrilaterals.

In an attempt to overcome such use of prototype-based reasoning, Yu, Barrett and Presmeg (2009) studied learners' prototypes and categorical reasoning through tasks using an interactive-based geometry environment. The tasks were designed to prompt the development of arguments about geometric relationships based on visualisation, spatial reasoning and geometric modelling - illustrating how appropriate instructional tasks can help students form more powerful idea through more advanced and more integrated prototypes.

\subsubsection{The theory of variation (or teaching with variation)}

The theory of variation (a theory of learning and awareness) has been developed by Marton (cf. Marton et al. 2004) and was first studied in geometry education by Leung (2008a, b) in the context of problem solving in a dynamic geometry environment. A basic tenet in the theory is to propose an organized use of different types of contrast to design or to interpret pedagogical processes. Contrast here means that, in order to discern something, one must experience some-thing else. This focus on differences creates a powerful way for learners to experience and discern critical features of the something to be learnt and to categorize different ways of experiencing that something. Building on the theory of variation, Leung (2012) proposed a progressive discernment sequence based on different levels of contrast to classify plane figures starting from awareness of visual intuitive features, next of geometrical properties, and finally of relationships between properties. The key idea behind this approach was on shifting attention to become aware of different types of critical features (e.g., visual, geometrical properties, and relationship between properties) and their logical connection. This was an attempt to further develop a nested epistemic model proposed by Leung (2011) to probe into 
variation could play an epistemic role in geometrical concept formation. Prototype phenomenon and this variation approach share a common focus as different types of critical features categorize different prototypical examples.

Teaching with variation, a theory of classroom teaching, was articulated by Gu (1992) and later by Gu et al. (2004). For geometry education, teaching with variation entails providing learning experiences in which there are different variations of figures (Ding et al. 2015; Jones \& Herbst 2011). Through these variations in exploring and comparing figures, learners extract essential features of the figures, while non-essential features are simultaneously disregarded.

\subsubsection{The cKф (conception, knowing, concept) model}

The cKф (conception, knowing, concept) model (c.f., Balacheff \& Margolinas 2005; Balacheff 2013) has a range of antecedents, including Vergnaud's notions of concept and conceptual field (see Balacheff 2013, for an account). It is, in essence, a framework to model the mathematical under-standing of learners, taking into account the situational characteristics. It does this by deeming a 'conception' as the quadruplet $(\mathrm{P}, \mathrm{R}, \mathrm{L}, \Sigma)$ in which: $\mathrm{P}$ is a set of problems; $\mathrm{R}$ is a set of operators; $\mathrm{L}$ is a representation system; and $\Sigma$ is a control structure.

Focusing on learners' conceptions of congruency, González and Herbst (2009) proposed the following four conceptions based on their theoretical analysis; the perceptual conception of congruency; the measure-preserving conception of congruency (MeaP); the correspondence conception of congruency; and the transformation conception of congruency. In analysing high school students' conceptions of congruency when tackling problems in a DGE, the authors concluded that "While measuring still does not promote the transformation-conception of congruency needed for a theoretical approach to geometric figures, its capacity to shift attention from shapes to properties could be the seed for students to discover new mathematical ideas and to go beyond visual perception" (p. 156).

Jones and Fujita (2013) built on this study by analysing the approach to triangle congruency in textbooks used in lower secondary school (specifically for students aged 13-14) in Japan. In the selected textbook, they found that the coverage of triangle congruency commenced with some practical tasks that could entail students developing various conceptions of congruency. The bulk of the coverage com-prised proof problems that expected students to have the 'correspondence' conception of congruency, as the main conception to solve problems: this despite the fact that many Grade 8 students in Japan do not fully develop their 'correspondence' conception of congruency.

\subsubsection{Discursive perspectives}

There are ample studies that focus on cultural-social and ecological geometry pedagogy. Rowlands (2010), for example, discussed a curriculum initiative that aimed to 'bring to life' major events in the history of Greek geometry to encourage discourse that could provide an opportunity to introduce students to formal abstract proof. Massarwe, Verner and Bshouty (2010) reported on a study where prospective teachers engaged in a workshop about construction and analysis of geometric ornaments from different cultures leading to teaching geometry in this context to middle school students. Creativities by the middle school students were observed in students when they constructed new ornament styles, discerned geometrical problems related to the ornaments and found different approaches to solve these problems. As discussed in Sect. 3, Owens $(2014,2015)$ developed an ecocultural approach on mathematics about space and geometry by researching with indigenous cultures of Papua New Guinea and Australia.

Both Kaur (2015) and Ng and Sinclair (2015a, b) use Sfard's (2008) communicational approach. Using this theoretical framing, Kaur shows how young children "developed a reified discourse on triangles, which involves inclusive descriptions of classes of triangles (in other words, they thought about equilateral triangles as special types of isosceles triangles)" (ibid p. 407). Ng and Sinclair (2015a) investigated young children's learning of reflectional symmetry. Ng and Sinclair (2015b) investigated 13-14 year old students' learning of area through a geometric approach, using shearing. In all three studies, the geometry was investigated using a dynamic geometry environment (DGE).

\subsubsection{Commentary on general theories used in geometry education research}

In studying how learners' prototypes can be progressively refined, a number of existing studies have revealed that a geometrical concept may have different characterizations depending on different foci of attention; for example, whether the geometrical ideas are visual, measurement, correspondence and transformation. Research by Kaur (2015), Leung (2008a, b; 2012), Ng and Sinclair (2015a, b), and others, shows that shapes in DGEs can be continuously transformed thus allowing great diversity for a recognized shape and hence a need to name a shape. As geometric dis-course develops when using a DGE, visual identification of a geometric shape should give way to a discursively-mediated process leading to a discursive procedure of a formal definition of the shape. 
Sinclair and Moss (2012) discuss a model of the development of geometric discourse and state that "the process of discourse change does not consist in smooth linear transition from one level to another; rather, it involves oscillating between the old and new forms of dis-course, resulting in intermediary hybrid forms of geometric communication" (p. 43). These statements echo the need to study the transition phases in the progress of geometrical concept formation. In this, theoretical frames such as prototype theory, variation theory, the $\mathrm{cK} \phi$ (conception, knowing, concept) model, and various discursive perspectives are all likely to be useful.

\section{Advances in the understanding of visuospatial reasoning}

Over the past decade, increased attention has focused on visuospatial reasoning (Healy \& Powell 2013; Lowrie, Logan \& Scriven 2012; Owens 2015). Others refer to this reasoning as visualisation and visualising (Clements 2012), spatial thinking (Newcombe \& Stieff 2012), spatial reasoning (Davis \& Spatial Reasoning Study Group 2015), visuospatial thinking (Shah $\&$ Miyake 2005), and visual reasoning (Rivera 2011) to name a few. These all have in common the activity of imagining static or dynamic objects and acting on them (mentally rotating, stretching, etc.). While visuospatial reasoning is arguably relevant in all areas of mathematics, it has particular significance in the teaching and learning of geometry. In this section, we pro-vide an overview of research undertaken both in mathematics education and in cognitive sciences, as well as research that was focused on sociocultural aspects of visuospatial reasoning. Across these research domains, there is converging agreement on the importance and malleability of visuo-spatial reasoning.

\subsection{Studies emerging from the cognitive sciences}

Recent research is showing how geometry has an intuitive experiential basis well before school (see Bryant 2008). Thus the spaces occupied and explored by children become significant not only for mapping but also for understanding basic geometric concepts such as boundedness, flat-ness, parallels, perpendiculars, curves, distance, and mapping. Young children use both geometric features of their surroundings as well as landmarks to find their way around spaces (Cheng, Huttenlocher, \& Newcombe 2013). For example, Lee, Sovrano, and Spelke (2012) found that 2 year olds used surface distances and directions. Spelke, Gilmore, and McCarthy (2011) showed that kindergarten children of both genders spontaneously extracted and used relationships of both distance and angle in the maps with-out prior demonstration, instruction or feedback. Cheng et al. conclude that, "the dominance of geometric information over feature use has turned out to depend critically on the size of the enclosure, with geometry more likely to be used in small spaces and features more likely to be used in large spaces" (p. 1043).

In the last few years, psychological studies have shown the effect of training of mental rotation on visuospatial reasoning. For example, Cheng and Mix (2014) have shown that training in mental rotation improved children's ability to solve problems such as $5+\ldots=14$. The researchers hypothesised that children's increased visuospatial reasoning enabled them to manipulate the terms of the equation. Uttal et al. (2013) carried out a meta-analysis of 217 training studies and showed the malleability of spatial abilities and their effects. The term 'malleability' foregrounds that spatial capabilities, defined as responsiveness to spatial tasks, can vary, change, improve, and be modified by training.

Importantly, Uttal et al. not only considered the effects on gender, but also looked at generally poorly performing students and age. In order to analyse such a diversity of studies, they categorised them along two dimensions: static-dynamic and intrinsic-extrinsic. In particular, they noted the difference in visualising of object visualisers (intrinsic-static) compared to spatial visualisers (intrinsic-dynamic). This is somewhat reminiscent of Owens' (Owens 2015; Owens, McPhail, \& Reddacliff 2003) study with activities that related to part-whole relationships including position and re-seeing, and those that related to orientation and motion including dynamic variation. It also sup-ports Tartre's (1990) earlier classification of spatial abilities in which visualisation included all forms of transformation such as making 3D shapes from 2D nets, and mental rotation.

Uttal, Meadow, Tipton, Hand, Alden, Warren and New-combe (2013) studied a wide range of spatial reasoning training studies, including video game training, long-term classroom or similar training, and short term, more repetitive 'laboratorytype' training. They found large effect sizes across the board, concluding that, "spatially enriched education could pay substantial dividends in increasing participation in mathematics, science, and engineering" (p. 352). The researchers noted that mental rotation training and video-game training were particularly prevalent in ensuring the threshold for STEM was reached.

Newcombe and Stieff (2012) drew on research to show that gender differences are limited to performance on a few spatial tasks and that training can overcome these differences. In addition, spatial development does start at an early age and develops through experience although some learning may be limited by maturation; it appears that most spatial skills begin early in life and continue to develop with experience. Finally, they show that language does not frame spatial thought 
but draws attention to features. Newcombe and Stieff (2012) recommended that, for all ages, genders, dispositions, experiences and cultures, educators motivate and harness visual approaches for understanding since there is little evidence for any of these factors actually influencing learning. This was supported by a large study by Jirout and Newcombe (2015) who took gender, SES, and spatial play into account and found little effect of these variables. They suggested that quality rather than quantity of block play should be taken into account in future studies.

Giofrè, Mammarella, Ronconi, and Cornoldi (2013) developed a complex visuospatial working memory task requiring the manipulation of visual information as well as culturally-mediated principles of geometry that directly predicted academic achievement in geometry for 4th and 5th grade Italian children. According to these researchers, the importance of visuospatial working memory is critical in learning geometry. Mammarella, Giofrè, Ferrara, and Cornoldi (2013) found that students (6-8th grade) with nonverbal learning disabilities (NLD), in particular, showed main difficulties with Euclidean geometry and transformations, but not with simple memory tasks. This is not surprising given that these children could be "characterised by a visuospatial weakness" (p. 244).

\subsection{Research emerging from mathematics education}

Within mathematics education, several studies have focused on improving visuospatial reasoning. For example, fourth graders (in New Hampshire, USA) showed an improvement in visuospatial thinking after a program involving origami and pop-up engineering, a program that appealed particularly to girls (Taylor \& Hutton 2013). Block play continues to be shown by research as an important experience in developing visuospatial reasoning in young children. In particular, differences between girls and boys can be reduced by a structured block-play program in which the teacher is aware of the expected trajectories of development for children (Tepylo, Moss \& Stephenson 2015). This adds to previous research on blockbuilding (e.g., Casey et al. 2008) and the large randomised study on technology interventions using Building Blocks (Clements, Sarama, Spitler, Lange \& Wolfe 2011). Furthermore, spatial experiences in childhood continue to show differences in adulthood in terms of visuospatial reasoning (Doyle, Voyer \& Cherney 2012). However, they do not account for more than $7 \%$ of the variance on metal rotation and water level tests.

Two studies showed that practical activities involving inquiry questions improved in their geometry knowledge and attitudes compared to control groups. One study involved visually representing a real situation (namely getting equal amounts of heat from a campfire) in grade 7 classes in Turkey (Duatepe-Paksu \& Ubuz 2009). Another involved developing concepts of 2D shapes [grades 4 and 5 in Mauritius (Jawahir 2013; Owens, Cherinda, \& Jawahir 2015)]. In these studies, drawing was seen as both a way of knowing children's visualisation but also an embodied tool for learning, as suggested in (Thom \& McGarvey 2015).

David and Tomaz (2012) argued the importance of visual representations in structuring learning. However, their analysis, based on Activity Theory, of a Brazilian classroom found that the dominance of seeing geometry as learning rules and norms created a tension in the incre-mental action of learning to calculate areas and use drawings for this purpose. In another study (Jo \& Bednarz 2014) that developed an assessment tool of teachers' disposition (in geography in this case), recognition was given to the importance of teachers valuing the teaching of visuospatial reasoning, spatial concepts and spatial representations.

Steenpass and Steinbring (2014) showed that children's discussions about visual representations are important in establishing the conceptual understandings of geometric knowledge and in understanding space (see also Vosnia-dou \& Skopeliti 2014, on physics concept of space). Rivera (2011) noted the complexity of reasoning about visual representations. In particular, different kinds of visuals are generated depending on the type of activity that is pursued, which could be imaginal (e.g., appeal to intuition), formational (e.g., concept or process developed), or trans-formational (e.g., problem solving). Individuals abduce the intended meanings of visual representations through the use of one strategy or more of the following strategies: learned pairings; manipulating corresponding iconic representations; associating with a relevant experience; and establishing relational structural similarities (Rivera 2011); see also Presmeg (2006).

An important study that teases out the processes of visual perception and perception-based knowledge representation was carried out by Gal and Linchevski (2010). They showed that both these processes affected geometry learning in early high school. They particularly noted that these processes consisted of perceptual organisation, that is Gestalt principles, recognition or a bottom-up or top-down processing and representation of perception-based knowledge dependent on verbal versus pictorial representation, mental images and hierarchical structure of images. Importantly, teachers became aware and could assist students knowing their processing difficulties.

\subsection{Focus on sociocultural perspectives}

Sociocultural studies have shown the impact of environment and a person's place in the environment on visuos-patial 
reasoning and geometry (Burgmanis, Krišjane \& Šķilters 2014). These researchers theorise that the learning of spatial knowledge in large spaces is influenced and structured by:

1. cognitive topology (comprised of a path and place structure of spatial information and constrained by reference framebased factors),

2. experience-based functional knowledge (including the effects of socio-economic factors, frequency and familiarity) and

3. linguistic representations (primarily encoded in the prepositional system of a natural language) (Burgmanis et al. 2014, p. 373).

Several studies have considered geometry in non-western developing countries that have an imposed western curriculum that is well-established in the thoughts of policy makers, curriculum writers, and teachers' understanding. One study in Nepal analysed the responses to a test used elsewhere in the world to find some significant differences in responses (Mainali 2008). Traditional teaching had resulted in students not being able to do rotation and reflection questions. However, after an intervention with collaborative inquiry groups using technology, the students improved their visuospatial reasoning. A study in Zambia (Haßler, Hennessy, Cross, Chileshe \& Machiko 2014; Wakwinji 2011) suggested that teachers were able to implement collaborative groups that used a DGE, but this required moving away from the traditionalist approach to teaching that had developed largely as a result of colonial backgrounds and lack of resources in schools. Part of their new knowledge was around visuospatial reasoning with the technological tools in generating formulae such as the area of a triangle from examples easily generated by the tools. The third study was in Ethiopia where a similar result occurred (Tessema 2007).

Owens (2015) has shown that Indigenous cultures have a close relationship to the land and represent it in cultural artefacts, stories, and values that differ from Euclidean geometries. Sometimes this is represented in different frames of reference from orthogonal grids, other times in association with time and storyline routes significant to the person and place. Particularly important is visuospatial reasoning that links change in one area to that of another such as length and volume or spaces (2D, 1D or 3D) with that of another. By establishing a strong sense of mathematics as processes rather than arithmetic facts and calculations, it may be possible to build on the strength of cultural mathematics and to promote strong transitions to school mathematics at all levels. In this way, the students' ecocultural identities can encourage self-regulation, ownership and responsiveness to encourage a strong mathematical identity (Owens 2015).

This perspective is supported by Luitel (2009) who shows the importance of seeing mathematics as an inclusive, multidimensional image that considers the unsettling 'impure' knowledge between systems and the importance of not reducing mathematics to a single exclusive system but to have a critical multilevel contextualisation of mathematics (Luitel 2013). Many studies have indicated that particularly Indigenous cultures made/make great use of visuospatial reasoning and reasoning connected to culture. In particular, studies informed by the Navajo in USA (Pinxten \& François 2011) indicate the immense visuospatial mental mapping of the canyon and in mathematical activities requiring proportional reasoning in Papua New Guinea (Owens 2015).

This perspective is supported by Mainali and Key (2012) who show that a series of inquiry learning (that also included the use of DGEs) experiences in a developing country encouraged students to develop their understanding of rotation and reflection and also changed the students' expectations about learning. One reason that this finding is important is that the students initially showed differences in responses to European students on a preliminary test of rotation and reflection. Furthermore, it was representative of change of perspective on the part of the teacher and students in terms of showing a change in seeing mathematics learning differently. In Luitel's (2013) terms providing a third space that overcomes the hegemony of mathematics as having to be learnt by rote or simplified for the students has encouraged mathematics to be seen as multifaceted and multilogical. In this way, mathematics has both local and global perspectives.

The implications of an alternative perspective have arisen in studies that not only note the importance of the teacher's cultural competency but also the importance of alternative curricula with an emphasis on visualisation provided by contextualisation (Duatepe-Paksu \& Ubuz 2009). Students stated that visualisation convinced them that what they learned was true. That is, visualisation was a kind of proof for them. Furthermore, student responses included that visualisation created an interest for the lesson.

\subsection{Concluding remarks}

Since geometry is a school mathematics topic that explicitly engages visuo-spatial reasoning, several authors have argued that an increased focus on geometry in the curriculum would be well advised (Sinclair \& Bruce 2015). In particular, given the importance of dynamic forms of spatial reasoning, highlighted in the work of Newcombe and others, and the relevance to motion and time across ages and cultures (humans live in a world that is constantly moving, changing), there is reason 
to conjecture that developing dynamic and haptic forms of visuospatial reasoning would have a positive impact on children's learning. There are interesting and long-standing mathematical challenges in moving away from paper-based static representations, taking inspiration perhaps from non-Western geometric ways of making sense of the world, but as shown in the Sect. 5, digital technologies can provide alternatives to such representations that offer learners more opportunities to create and reason with dynamic imagery.

\section{The use and role of diagrams and gestures}

The research described in this section has largely emerged out of recent emphases on the semiotic and embodied nature of geometry thinking and learning. In what follows we consider historical-cultural perspectives that highlight the role of semiotic processes and artefacts in geometry teaching and learning. In Sect. 4.2, we consider embodiment perspectives that have highlights the roles of gestures and diagrams in geometry teaching and learning.

\subsection{Historic-cultural perspectives: semiotics and artefacts}

We start from an example, still related to the interplay between geography and geometry, that has the potential to introduce the role of concrete artefacts in this discussion. The project Globolocal ( http://www.globolocal.net/eng/ index_eng.html) was begun in Italy. It draws on the importance of cartography in Europe since the time of the great explorations, but with a more 'democratic' attitude that has fostered connections with several countries spread all over the world (Italy, Spain, Portugal, Poland, France, Argentina, Peru, Chile, Antarctica). This project is built around a special artefact, the Parallel Globe, that helps everyone to better visualise their own position on the Earth surface in relation to the position occupied by other countries. The Parallel Globe is a simple tool that allows one to see how the Sun illuminates the different regions of the Earth in real time, helping one to understand the time zones (see Fig. 1). Besides, it allows one to understand the alternation of the seasons on the planet and it helps to more fairly treat all countries. The website contains documentation of the project from several countries.

The function of concrete artefacts, such as the parallel globe, has been studied inside different theoretical frame-works. Here we mention the framework of semiotic mediation (TSM) after a Vygotskian approach (Bartolini Bussi \& Mariotti 2008) that has been developed in connection with several classroom experiments where the emphasis is on the semiotic activity developed around a given artefact (including also ICT) to solve a given task under the teacher's cultural guidance.

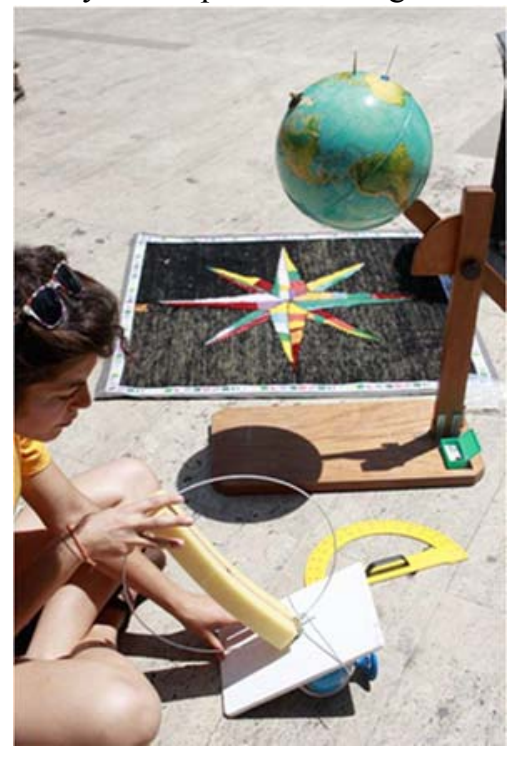

Fig. 1 An educator playing with a parallel globe in Rome
The semiotic activity produced by students and exploited by teachers is exemplified by oral or written language, drawings and diagrams, and gestures. In several cases, geometry has been addressed to explore copies of historical artefacts such as instruments to draw parabolas (Bartolini Bussi 2010) at secondary level; instruments for perspective drawing at primary level (Maschietto \& Bartolini Bussi 2009). These artefacts are part of the history of mathematics education in different countries (Bartolini Bussi, Taimina \& Isoda 2010).

The deep interplay between the handling of concrete artefact and the development of gestures (beside drawings and speech) is clearly shown by Maschietto and Bartolini Bussi (2009). A teaching experiment on perspective drawing at primary school (fourth to fifth grade classes) is reported. It starts from a concrete experience with a Dürer's glass to the interpretation of a new artefact, representing a visual pyramid: This model is made of wooden poles with threads forming the edges of a pyramid (visual rays). Each thread passes through a hole in a wooden horizontal place and is fixed inside another hole in a small Plexiglas plane (intersection plane).

These studies highlight the significant mediation process that is required in the use of artefacts, thus echoing Pimm's (1997) observation that the mathematics cannot be found within any particular manipulative. Indeed, the TSM provides a powerful way for teachers and researchers to study and appreciate the process by which activity with artefacts can be turned into mathematical signs, particularly through careful attention to hand and body movements. 
Fig. 2 a Young children (1st grade) playing with bee-bot on the floor, $\mathbf{b}$ young children (1st/2nd grade) playing with the dynamic symmetry machine
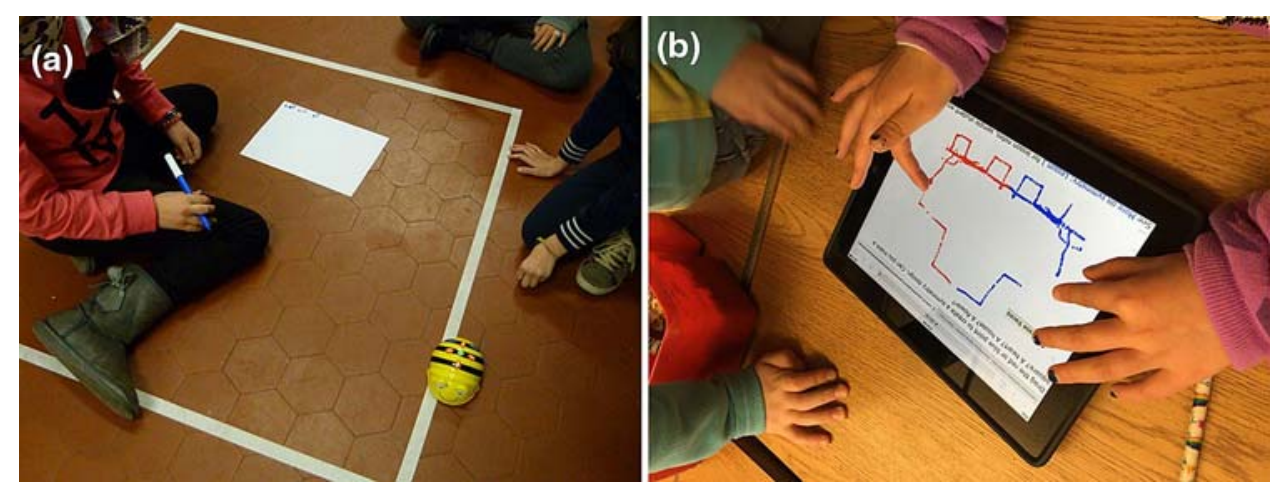

\subsection{Embodiment: gestures and classroom applications}

Multimodality, in particular involving bodily gestures, has been regarded as a driving force for the formation of geometrical understanding in the context of teaching and learning. Indeed, there is a growing number of papers where the study of gestures is considered essential in the construction of mathematical meaning (see the special issue 70(2) of ESM, published in 2009). The study of gestures, drawing on the work of Kendon, McNeill, Goldin-Meadow and Kita [and earlier of Vygotsky himself, see Sabena, (2008) for a review], has been connected with the theoretical approach to embodiment (Lakoff \& Nunez 2000). Learning processes exploit also perceptual-motor components, hence the body becomes essential in the teaching and learning processes. Gestures are semiotic resources that students and teachers use in the classroom, both as spontaneous forms of communication, and as explicitly learned signs.

Fyhn (2008) reported a study where students mathematize their climbing with respect to angles, creating a link between their climbing gestures with texts and drawings. Roth and colleagues (Bautista \& Roth 2012; Kim, Roth and Thom 2011) have developed a complex set of studies about geometrical objects where the link between the body and the linguistic acts are emphasised up to the discovery of what the authors call sonorous consciousness, as sound has the potential to mark mathematical similarities and distinctions. These 'audible' similarities and distinctions, which may be produced by incarnate dimensions such as beat gestures and prosody, allow children to objectify certain geo-metrical properties of the objects with which they transact. Moreover, the analysis shows that sonorous production is intertwined with other dimensions of students' bodily activity. Kim, Roth and Thom (2011) while contesting knowing as a mental process detached from the physical world identified claims that students' gestures support, co-emerge with, cope with and exhibit (embodied and abstract) knowledge of geometry. Morgan and Alshwaikh (2012) reported in an experimental teaching programme making use of a LOGO-like formal language for constructing 3D trajectories and figures in a computer micro-world, a system of similar gestures emerged from the teachers and students to represent different types of movement.

The simultaneous presence of the body experience, the perception of sounds and path, the production of gestures and other signs is also at the foreground of another teaching experiment on the approach to inclusive definition of squares and rectangles (Bartolini Bussi \& Baccaglini-Frank 2015) by means of programming a small robot (bee-bot) (see Fig. 2a). Ng and Sinclair (2015a) show how grades 2/3 children use gestures to communicate central ideas about reflectional symmetry, such as the equidistance from the line of symmetry (see Fig. 2b). In connection with the work of gesture researchers such as Goldin-Meadow (2003), these examples show how learners can sometimes communicate visual, dynamic ideas through gestures before they can do so verbally. Researchers have also focused on the gestures used by teacher. For example, Shein (2012) videotaped interactions in a 5th grade mathematics classroom and studied the gestures used by the teacher for how they helped students work on geometric tasks.

The implication of embodied approach for students with special needs is emphasised by Healy and Fernandes (2011) who study the role of gestures in the mathematical practices of blind students. They argue that cognition is both embodied and situated in the activities through which it occurs and that mathematics learning involves the appropriation of practices associated with the sets of artefacts that have historically come to represent the body of knowledge we call mathematics. This process of appropriation involves a coordination of a variety of the semiotic resources - spoken and written languages, mathematical representation systems, drawings, gestures and the like-through which mathematical objects and relationships might be experienced and expressed. To highlight the connections between perceptual activities and cultural concepts in the meanings associated with this process, the authors concentrate on learners who do not have access to the visual field. More specifically, they present three examples of gesture use in the practices of blind mathematics studentsall involving the exploration of geometrical objects and relationships. On the basis of the analysis of these examples, the 
authors argue that gestures are illustrative of imagined re-enactions of previously experienced activities and that they emerge in instructional situations as embodied abstractions, serving a central role in the sense-making practices associated with the appropriation of mathematical meanings.

\subsection{Links between gestures and diagrams}

While research on gestures and on diagrams has long been pursued independently (de Freitas and Sinclair 2012), there has more recently been growing interest in the relation between gestures and diagrams in mathematical thinking and learning. Already in 1999, the philosopher and historian of mathematics, Gilles Châtelet, had drawn attention to the interplay between gestures and diagrams in the invention of mathematical ideas, drawing on historical evidence. He underscored the way in which gestures can lead to new diagrams that can support inventive reasoning, and in which diagrams can themselves engender new gestures. He argued that neither the gesture nor the diagram should be seen only as representations, but instead also as constituting the very material basis for the mathematical thought experiment. de Freitas and Sinclair (2012) illustrate this creative nature of diagramming by examining the diagrams that University students (non-mathematics majors) produced based on dynamic imagery of growing circles.

Chen and Herbst (2013) compared the interactions of students working with a diagram that contained all the labels (for vertices and angles) that were needed to carry out the proof, with those of students working with a diagram that contained no such labels. In the first case, students only used pointing gestures. In contrast, the students in the second case made gestures that extended existing lines or summoned invisible intersections and angles, as if to give the existing diagram new geometric elements - thus leading to generative modes of interaction with the diagram. These gestures prompted students to speak about hypothetical objects and properties. The authors concluded that the "gestures played a crucial role in engaging students in reasoned conjecturing" (p. 303) because the gestures gave rise to hypothetical objects that the students could make and justify conjectures about.

These findings are in line with those of Sinclair, de Freitas and Ferrara (2012), who examined first grade children's reasoning about intersecting lines that were displayed using a DGE. The dynamic diagram contained two lines that could be dragged on the screen. In order to justify when two lines would intersect, even if their point of intersection was not visible, the children created two distinct gestures: one involved extending the lines off the screen, either with fingers or whole arms, to create the hypothetical point of intersection; the other was to use finger and thumb to mark the distance between the lines. In this case, the dynamic diagram gave rise to gestures than were productive for the students' reasoning.

\subsection{Concluding remarks}

Researchers have also begun to study the role of gestures and diagrams in the work of professional mathematicians, both as researchers (Menz, 2015) and as lecturers (Barany \& MacKenzie 2014; Hare \& Sinclair 2015). This work corroborates some of Châtelet's claims, while also providing more detailed and real-time evidence of the meanings that gesturing and diagramming help to create, even in highly advanced mathematics. This work, combined with the studies summarised before, provide a clear indication of the importance of encouraging learners to engage in more gesturing and diagramming. Existing research suggests that the more teachers gesture, the more students will, but future work could provide insight into the types of gestures that might be helpful and the modalities in which students are invited to gesture as well. A more challenging area of research relates to increasing students' experiences with diagramming, which will involve both helping students develop stronger diagramming practices and providing contexts in which diagramming is valued and productive. Finally, with the increased presence of touchscreen technology, where gesturing and diagramming can reach a completely new form of interplay, we expect increased research in this area (see Sinclair \& de Freitas 2014).

\section{Advances in the understanding of the role of technologies}

Despite the fact that the role of technologies has not been understood completely or explored in enough detail since the introduction of DGEs The Geometer's Sketchpad and Cabri-Géomètre in the early 1990s, new technological developments over the past decade have led to new challenges in the use of technology in the teaching and learning geometry. This demonstrates the importance of three areas of research: (1) the introduction and design of new technology, both hardware and software, (2) theory and methodology for a better understanding of the role of existing and emerging technology, and (3) empirical studies on the use of technology in teaching and learning. Across these three areas, the use of the framework of instrumental genesis (Verillon \& Rabardel 1995) is evident. In terms of empirical studies, research on the conjecturing and proving processes when using technology is covered in Sect. 7. 


\subsection{Digital technologies for geometry teaching and learning, and their design}

The availability of digital tools, in particular DGEs, has rapidly changed over the past 8 years. The arrival of the freelyavailable GeoGebra made DGE affordable and available for anyone, but it also undermined the educational software market in Geometry that originally had room for several different DGEs - not only the original pack-ages The Geometer's Sketchpad (Jackiw 1989) and Cabri-Géomètre (Baulac, Bellemain \& Laborde 1988) but also more than 50 other products with various licensing models. Some of them, including Sketchpad and Cabri, are still available, but it has become difficult for independent developers or companies to maintain or launch alternative DGEs. Mackrell (2011) discusses the matter of design decisions for interactive geometry software comparing Cabri, Sketch-pad, Cinderella (Richter-Gebert \& Kortenkamp 2012) and GeoGebra, and shows that a certain variety of approaches is desirable. She also highlights the fact that consistent educational design of a DGE is difficult to achieve. A niche product worth mentioning is Geometry Expressions (Saltire Software 2016) that follows a relational approach to geometry (where the geometry is modelled using a constraint-based symbolic geometry system), as compared to the common functional constructive approach (where geometric configurations must be expressed in terms of sequential constructions).

\subsubsection{Geometry on the web}

Geometry on the web has been possible since the introduction of Java applets (for example, JavaSketchpad was released in 1999). Unfortunately, this technology has been deprecated and is being replaced by JavaScript and HTML5. For teachers and learners this means that many websites containing interactive geometry resources have ceased to work. GeoGebra solved this problem by providing a JavaScript runtime, but at the same time web export was restricted to the GeoGebraTube platform. An alternative approach is the JSXGraph library (Gerhäuser, Valentin \& Wassermann 2010), that powers Sketchometry (Ehmann et al. 2013) and the CindyJS Project (2015). Both can be used to replace Java and run interactive geometry on the web again.

\subsubsection{Interface design}

Traditional DGE research on user-interface design has led to new insight that has added to what is already known about uses of reduced menu configuration for geometry software. Kortenkamp and Dohrmann (2010), for example, describe basic user interface issues and approaches to address them. Schimpf and Spannagel (2011) compared full and reduced icon sets in DGEs with eye-tracking technology and found no significant effects of graphical user inter-face (GUI) reduction on the findability of already-known icons. Jackiw and Sinclair (2009) discuss how the concept of 'dynamic mathematics' involving new mathematical structures and their auditory and visual representations - can carry the concept of dynamism from DGEs in both its mathematical aspect of continuity and its pedagogic aspect of immediacy. They focus on the second aspect "in evaluating how novel dynamic representations in GSP5 affect mathematical modelling opportunities, student activity and engagement" (p. 413). This topic is further addressed by Laborde and Laborde (2014), who see three dimensions of transformation in mathematics and mathematics education: an epistemological dimension, a cognitive dimension, and a didactic dimension. In a chapter of the 17th ICMI Study, Jones et al. (2010) focus on the design of digital technologies for activities in Euclidean and non-Euclidean geometries and find that design decisions must take both the learner and the mathematical content into account.

\subsubsection{Mobile devices and touch technology}

Dragging remains the most important feature of DGEs; Baccaglini-Frank \& Mariotti (2010) investigate this particular feature in more detail, while Forsythe (2015) links dragging strategies to perceptions of symmetry. Mariotti (2014) explores the semiotic potential of the dragging tool for introducing the notion of conditional statements and how personal meanings emerging from students' activities in a DGE can be transformed into mathematical meanings. Leung (2008a, b) further differentiates various discernment modes and relates variation and dragging, also by presenting the epistemological potential of Parametric Colors in Sketchpad, which adds spectral dragging to the known dragging modalities by Arzarello et al. (2002). González and Herbst (2009) investigate students' interactions with dynamic diagrams in conjunction with measuring, see a shift of focus from shape to properties, and describe a functional mode of interaction with diagrams, where output and input are related when dragging a figure.

The biggest change for technology-based geometry teaching is the wide availability of mobile devices with touch screens. Students are familiar with these devices, and tablet devices offer enough screen estate to do geometry. Using tabletbased DGE (GC/HTML5 by Iijama 2012), Arzarello, Bairral and Danè (2014) conducted a case study where they observed Italian high school students and found new modes of touchscreen manipulation that they suggest, "opens a new stream about dynamic geometry in multi-touch technology" (p. 39). Similarly, Ingraham (2013, p. 67) describes how a tablet can 
be used to "drastically change the way educators present material, and the way students demonstrate their knowledge of subject matter". Ng and Sinclair (2015b) report on geometry lessons where features of a touchscreen DGE support the learning of junior high school students. Lai and White (2014) present an interesting setup where students work collaboratively in groups of four to drag the four vertices of a quadrilateral using mobile devices as part of a larger research project. The students showing more collaboration were also demonstrating better individual learning outcomes.

While mobile devices offer new possibilities for the integration of technology in geometry teaching, the design of the user interface needs careful analysis. Isotani et al. (2014) propose and implement an interface and interaction model that is suitable for developing DGEs for mobile devices. Jackiw (2013) describes the influence of multi-touch for Sketchpad Explorer as another new feature for DGEs, which enables users to drag multiple objects simultaneously and gives rise to potentially new activity implementations as well as mathematical conceptualisations. Su et al. (2014) describe their GeometryTouch system and how they handle dragging in drawing sequences that involve several points.

\subsection{Research in specific tools and concepts}

Research on the use of certain DGE elements includes the work of Bu and Haciomeroglu (2010) who examined the specific role of sliders in DGEs. Psycharis and Kynigos (2009) investigated the use of sliders as a means of dynamic manipulation for activities realized with Turtle-Worlds in LOGO and describe the actions of the students in four distinct dynamic manipulation schemes (reconnais-sance, correlation, testing, verification). Gol Tabaghi and Sinclair (2013) showed that DGEs can support students in the development of synthetic-geometric modes of thinking, and also connect this to embodied mathematics, coining the notion of dynamic-synthetic-geometric thinking. Lee and Chen (2014) included prior knowledge as a variable in their experimental design, comparing virtual and physical manipulatives and find that "students with high prior knowledge using virtual manipulatives had better post-test performance than did the physical manipulatives group, and reported taking greater enjoyment in mathematics" (p. 179).

From an ecocultural perspective, Owens (2014) consider digital technological facilities as an ecological context and discuss "how a computer-facilitated learning age influences an ecocultural identity and both self-regulation and visuospatial reasoning" (p. 275). Yang and Chen (2010) show that a digital pentominoe game can significantly improve spatial abilities as well as reduce the gender differences between boys and girls. Spatial capabilities can be strengthened using 2D software, as Hung et al. (2012) show based on a cognitive analysis approach for game-based learning. What is more, Bonnard et al. (2012) describe paper interfaces, where traditional conventional school tools are merged into an augmented reality system for learning geometry, and observe that these can be easily adopted into traditional classroom practices. Also without digital technology, Arici and Aslan-Tutak (2015) found that an intervention with origami-based geometry instruction had a significant effect on spatial visualization, geometry achievement, and geometric reasoning.

\subsubsection{D approaches}

Spatial geometry has also become accessible through technology: Cabri 3D and other specialized DGEs are now available. Even so, 3D manipulation in augmented reality has yet to become mainstream. Güçler et al. (2013) examined 10-year-old students using haptic devices in dynamic multi-modal environments, with preliminary findings showing that such technologies "have the potential to pre-sent students with the opportunities to explore 3D objects through multiple perceptions, supporting meaningful dis-course as students engage in mathematical activities such as exploring, conjecturing, negotiating meaning, and sense-making" (p. 97).

Chang et al. (2014) used tablet PCs capable of running Cabri 3D to create a mobile learning environment for spatial geometry and their results indicated improvements in spatial geometry scores in the experimental group. More cautionary results were found by Perry and Steck (2015) who point to the difficulties in controlling variables within an experimental design. Their study shows mixed results for the effect of using iPads in geometry education with regards to student engagement, geometry standards proficiency scores, self-efficacy and meta-cognitive self-regulation. Latsi and Kynigos (2012) used 3D turtle geometry and found that students experience the simulated 3D space through two distinct perspectives, the intrinsic perspective of the turtle and the extrinsic perspective of an external observer.

\subsubsection{Tutoring and recording students' answers}

Richard et al. (2011) work on intelligent tutorial systems based on GeoGebra, both reviewing the existing sys-tem and creating new theory linking didactical contracts and formal computer science models. Besides video and screen recording, new methods for recording student learning processes and making them accessible for quantitative research have been introduced. Leung and Lee (2013) created a DGE-based platform that was capable of generating a collective image map of 
student geometrical perceptions for a pre-designed dragging task. This map is called a task perceptual landscape. It is visually interpreted as students' qualitatively different ways, which are quantified and categorized in a collective way, of perceiving a geometrical phenomenon under the drag mode.

\subsubsection{Task design with technologies}

Designing tasks that make suitable use of the affordances of digital technologies has been tackled by a number of researchers. Both Fahlgren and Brunström (2014) and Leung (2011) propose models for the design of tasks that foster students to make generalizations by capitalising on the drag-mode within DGEs. Meanwhile, Trgalova et al. (2011) showed how the idea of involving teachers in evaluating the quality of tasks is a "promising way of stimulating the use of dynamic geometry in classrooms" provided that teachers "benefit from support to make the quality pro-cess their own" (p. 337). The focus of Hung, Hwang, Lee and $\mathrm{Su}$ (2012) was developing game-based spatial learning tasks that they found improved the spatial sense of elementary school students. They propose a cognitive analysis approach for developing such spatial learning tools.

\subsubsection{Teacher education and professional development with technologies}

Stols and Kriek (2011) report that "beliefs about the perceived usefulness" and "beliefs about their level of technological proficiency" are "the most important predictors of teachers' intended and actual usage" of a DGE. Lavicza et al. (2010) conducted a study of a professional development network in England established around dynamic mathematics software. They found that the success of the professional development activities was "highly depended on the accessibility, sharing, and exchange of resources and ideas among participants" such that "developing on-line, easily accessible and searchable local resources is crucial for the future" (p. 181). As Hodge and Frick (2009) conclude, there is a need for further research on the preparation of teachers to help them ensure that students gain deeper understanding of geometrical concepts and theory.

\subsection{Concluding remarks}

Technology in geometry education has become mainstream; but there is still not enough research into its specific effects. This is in part due to the way that some technologies, such as DGEs, change geometric objects and dis-course quite significantly, as compared with paper-and-pencil approaches - something that can make articulation in the classroom, with textbooks, physical manipulatives and, especially assessment (Venturini 2015), quite challenging. The role of technology is just beginning to be understood, while, at the same time, it continues to evolve and rapidly change the world around us and in the classroom. Students and teachers are using digital tools throughout the day, and it is necessary to better understand how they can be used effectively for teaching and learning.

\section{Advances in the understanding of the teaching and learning of definitions}

Formally, mathematics is seen today as being built up from carefully stated axioms and definitions as the starting points from which theorems are developed and proved, but the complete, rigorous axiomatization of geometry is a problematic challenge (Smith 2010). The axioms and definitions of mathematics are no longer seen to be 'self-evident' truths. Instead they are viewed as necessary assumptions to avoid issues of logical circularity and infinite regression. They are starting points, often conveniently chosen, for the development of a deductive system; locally in the case of definitions for concepts such as the quadrilaterals; globally in the case of axioms for a theory (Freudenthal 1973).

The importance of definitions is reflected in the research literature, with many studies on this theme appearing over the past decade. In the overview that follows, we consider research that focused on the following themes: understanding the process of defining and the need for definitions; and, understanding of triangle and quadrilateral definitions. We close with some comments on areas of research that have been not been adequately addressed.

\subsection{Understanding the process of defining and the need for definitions}

Mathematically, two different kinds of defining as a mathematical process can be distinguished; namely, descriptive and constructive defining as described in De Villiers (2004). It would seem that most mathematics education research has in recent years concentrated largely on the process of descriptive defining (e.g., Choi \& Kim 2013). A descriptive approach to defining a circle with 12 to 13-year-old students via modelling using Play-Doh was reported by Neel-Romine, Paul and Shafer (2012), involving students in writing and critiquing possible definitions for a circle. 
Zandieh and Rasmussen (2010) effectively used the ideas of concept image and concept definition in a basically descriptive (a posteriori) way to explore the meaning and definition of a triangle with undergraduate students by considering extreme cases (e.g., vertices in straight line) as well as contrasting planar triangles with spherical ones. The comparative approach to teaching geometry developed by István Lénárt similarly involves the simultaneous, initial introduction of geometric concepts such as lines, triangles, angle, etc. by contrasting the plane and spherical versions of concepts to develop deeper understanding, and the evolution of more general definitions of the concepts concerned (Rybak \& Lénárt 2012).

Within the context of polyhedra, Ambrose and Kene-han (2009) conducted a teaching experiment following a descriptive approach to defining. Firstly, the 8- and 9-year-old children built and described polyhedra during several lessons, and examining a range of examples and non-examples progressively enculturated students into developing precise, formal definitions for components.

The gradual building of concept images with young children in line with eventual concept definitions is also advocated and illustrated by Levenson et al. (2011) in an essentially descriptive (a posteriori) order.

\subsection{Understanding of triangle and quadrilateral definitions}

The potential of a DGE to develop an understanding of, and reasoning about, the properties and behaviours of different triangles (scalene, isosceles, equilateral) with young children (ages 7-8, grade 2/3) was researched by Kaur (2015). The discourse focused on the behaviour of pre-constructed triangles as the children dragged their sides and vertices, thus generating many non-prototypical examples, and from the evidence, assisted children, for example, to think inclusively about equilateral triangles as special types of isosceles triangles.

Usiskin et al.'s (2008) monograph reported on a systematic analysis, which they call a micro-curricular analysis, of various textbook definitions in the USA that have over the years been given to quadrilaterals. Most importantly, it addresses the issue of how a specific quadrilateral can be mathematically defined in different equivalent ways, as well as that the definition could be chosen to be inclusive or exclusive. Similar to De Villiers (1994), the monograph extensively explores the advantages of a hierarchical approach. The specific case of defining a trapezoid (trapezium) either inclusively or exclusively is also discussed in Popovic (2012), and the consequences of those choices.

Building on substantial prior research, Fujita and Jones (2007) explored the gap between the personal and formal figural concepts of learners in a primary mathematics teacher course and also for learners at school in relation to the hierarchical classification of quadrilaterals. Though the majority of students were able correctly to draw representations of squares, rectangles, etc., most of them were unable to produce correct hierarchical definitions for the quadrilaterals. Their main finding is that learners appear to be very strongly influenced in their choice of definition by proto-type images of quadrilaterals, often leading to partition definitions or uneconomical ones (compare De Villiers, et al. 2009; Foster 2014).

Findings by Atebe and Schäfer (2008) in a comparative study of a group of Nigerian high school (ages 16-18) students with a South African group similarly showed that class inclusions of quadrilaterals were almost completely absent. Their work, like that of Markovic and Romano (2013), also showed how students frequently used imprecise terminology and mistook necessary for sufficient conditions in the context of identifying and defining quadrilaterals. Similar findings about elementary school teachers understanding of quadrilateral definitions have been made by Choi, Oh and Kyoung (2008). In a longitudinal study involving prospective secondary mathematics teachers, Van Putten (2008) found that even after four months of geometry instruction, many of the students were not yet at Van Hiele level 3, which is where the formal understanding of definitions are hypothesised to be located.

Fujita (2012) further investigated the relationship between prototype phenomenon and learners' level of understanding of the inclusion relations of quadrilaterals. His findings were that more than half of the (above aver-age) learners were likely to recognize quadrilaterals primarily by prototypical examples (i.e. concept images), even though they knew the correct, formal definition, and this caused them difficulty in understanding the inclusion relations of quadrilaterals. In other words, their choices are influenced by restrictive visual and mental representations such that a parallelogram, for example, has to be 'slanted' as clearly evident excerpts of learner responses.

Okazaki (2009) proposed the use of analogy as a useful strategy to challenge and develop learners' prototypical phenomenon. For example, if a learner accepts a square as a special type of rectangle, then we could apply analogical reasoning to other relationships such as the rectangle and the parallelogram. Building on this work, Fujita (2012) proposed a sequential plan for engaging learners with the complex issue of hierarchical definitions of quadrilaterals, which involves first eliciting the learners' understanding of quadrilaterals, then encouraging them to consider the opposing direction of inclusion relationship between definitions and attributes, and then discussing critical and non-critical attributes based on what they already know (analogical reasoning).

Both Okazaki and Fujita (2007) and Fujita (2012) focus on the importance of identifying learners' developmental paths leading up to their eventual definitions. Specifically it is reported that Japanese learners' path might be square/ rhombus, 
rectangle/parallelogram and finally square/rectangle. Another different technological approach towards an inclusive definition of squares/rectangles was explored with young children by using a programmable robot with LOGO-type instructions (Bartolini Bussi \& Baccaglini-Frank 2015).

Gal and Lew (2008) introduced Korean ninth-grade low achievers to parallelograms via dynamic and continuous shape changes using parallelograms made of strips and hinges. This seemed to help learners enlarge their concept image of a parallelogram as a dynamic figure that could change into a variety of different multi-named-objects - particularly into the special cases of rectangles, squares and rhombi.

Making use of dynamic geometry multimedia software in a SmartBoard environment, Leung $(2008 \mathrm{a}, \mathrm{b})$ found that 9year-old students could, after only three lessons, explain why a square is a rhombus (inclusion) as well as a parallelogram (transitivity). The drag-along action on several rhombi yielded static images of various rhombi and showed students that they could continuously change from one stage to the other. It seems that the effect of "animation-on-demand" offered by DGEs enhanced the teaching and learning effectiveness of class inclusion, and hence laying the conceptual foundation for the development of formal, hierarchical definitions later.

Like Sáenz-Ludlow and Athanasopoulou (2007), De Villiers et al. (2009) found that asking prospective mathematics or current teachers to first dynamically explore the properties of a less familiar quadrilateral such as an isosceles trapezoid and then to produce different correct definitions provided a very, rich instructive activity. Not only did it give insight into students' understanding of the general nature of definitions, but also an opportunity for the explicit discussion of necessary and sufficient conditions, as well as the choice between inclusive and exclusive definitions.

Okazaki (2013) aimed to clarify aspects transitioning from empirical to deductive recognition in terms of how fifth graders construct geometric definitions as their deter-mining conditions. Through design experiments, they identified five situations in which students enhanced their recognition of such definitions: (1) understanding the meaning of identifying geometric figures, (2) constructing examples from non-examples and justifying the constructions via comparisons, (3) recognizing equivalent combinations, (4) examining undetermined cases via counterexamples, and (5) conceiving figures as relations beyond the given actualities.

A study by Salinas et al. (2014) regarding teachers' use of quadrilateral definitions indicate that their own and their students' interactions may be more heavily influenced by their use of everyday language than by the role of for-mal definitions within mathematics. The complex issue of everyday language is also alluded to by Foster (2014) and Maschietto and Bartolini Bussi (2009) in relation to the whole problematic around class inclusion and special cases.

\subsection{Concluding comments}

It appears that the fundamental issue of understanding the need for accepting some statements as definitions to avoid circularity has been largely under-researched in the mathematics education community. Another under-researched area seems to be exploring the existence of a mathematical choice between defining (and classifying) the quadrilaterals hierarchically or in partitions (compare de Villiers 1994; Usiskin et al. 2008). A specific research question in this regard might be to investigate to what extent students and teachers understand (or how can this understanding be developed?) that choosing a hierarchical definition over a partition one, for example, leads to a more economical (shorter) definition, more concise formulation of some theorems, simplifies the deductive structure substantially by decreasing the number of proofs required, and assists in problem solving.

The mathematics research education community also has not much explored or tried to incorporate a more modern approach to defining (and classifying) concepts such as quadrilaterals using the notion of symmetry and transformations (compare De Villiers 2011; Hollebrands 2007; Usiskin et al. 2008) rather than the traditional focus largely on properties of sides, angles, etc. Further, little or no research has been done on developing students' capability to constructively (a priori) define concepts on their own. This is despite the fact that many mathematicians and educators have argued against the direct presentation of definitions, as a finished product to students, mainly because real mathematical research does not start with definitions, but with problems, and that definitions and axioms are mostly put in place at the end of the process (De Villiers et al. 2009).

\section{Advances in the understanding of the teaching and learning of the proving process}

Much research over the past decade has focused on studying the teaching and learning of the proving process, particularly in light of the increasing use of educational technology. Researchers have turned their attention to the following questions, many of them of perennial interest: What is and what constitutes a mathematical proof? How to interpret proof as an explanation that convinces others, and what makes something convincing? What kind of pedagogy and pedagogical tools are conducive to the construction of proof?

\subsection{The nature of proof}

Jahnke and Wamback (2013) explored how grade 8 students understood the nature of proof in a classroom teaching 
intervention approach where the teacher and students attempted to model the path of the sun (referring to the work of ancient Greek astronomers). An interesting finding was that students regarded the making of hypotheses as something that was only required in ancient times, where the instrument of observation were not as well developed as they are today. The authors comment that the histori-cal context might have exacerbated this view of hypotheses. However, the students did become "conscious of the role of assumptions in the process of building a deductive theory" (p. 482). Also with a historical perspective, Mout-sios-Rentzos and Spyrou (2013) used a phenomenological perspective to look at the socio-cultural factors that lead to geometrical proof in ancient Greek with an aim to foster present-day students' appreciation for proof. They posited that, "students' appreciation of proof lies in their acknowledging the existence of commonly accepted notions within which the geometrical objects are built" (p.334).

These studies point to a common theme that (geometrical) proof is socio-culturally bounded and is intimately related to the perceptual world, thus opens up a possibility, especially in the pedagogical context, to discuss alternative compatible frameworks for "what a geometrical proof is" that may be more empirical based. The nature of proof is fluid as its status may change depending on the process of acquiring geometrical knowledge is, in particular, the conjecturing process, and on the tools used in such process.

\subsection{Conjecturing process in dynamic geometry environments}

Draggable visual dynamic figures in DGEs have been playing a vital epistemic role in studies that probed the process of generating geometrical conjectures. Leung $(2008 \mathrm{a}, \mathrm{b})$ showed how a DGE-type geometrical conjecture could be reached via a systematic sequence of strategies based on building contrast and variation dragging experiences in DGE. BaccagliniFrank and Mariotti (2010) proposed Maintaining Dragging (MD) as a specific dragging mode that occurs during DGEbased conjecture production. In particular, the authors describe how a DGE exploratory phase could evolve into the basic components of the formal statement of a mathematical conjecture. Baccaglini-Frank (2011) further discussed how using MD to perceive two levels (a meta-level and a dynamic exploration level) of conjecture generation under abduction. Leung, Baccaglin-Frank and Mariotti (2013) later combined the lens of variation perspective and the MD mode to discuss a discernment of invariants model in DGE. The model built on types of variation awareness and simultaneity, and sensorimotor perception leading to awareness of dragging control to distinguish two levels of DGE invariants that could lead to formation of conjecture. In a related study, Mariotti (2014) used the theory of semiotic mediation to identify the semiotic potential of the DGE dragging tool for introducing the notion of conditional statement. The conjecture production process was seen as a semiotic process that involved a transformation from personal signs to mathematical signs. Specific dragging modalities related to the meanings of premise, conclusion and conditional were analysed. Taken together, these studies have generated alternative perspectives to re-conceptualizing the proving process in DGEs.

\subsection{Explanation and proof in dynamic geometry environments}

A tension exists between the empirical nature and the theoretical nature of mathematics. Arzarello et al. (2012) examine how this tension "regulates the actions of students who are asked to solve mathematical problems by first making explorations with technological tools, then formulating suitable conjectures and finally proving them" (p. 98) This was illustrated through student-centred analyses using four theoretical constructs: almost-empiricism and experimental mathematics, abductive versus deductive activities in mathematics learning, cognitive unity between arguments and proofs, and negation from a mathematical and cognitive point of view. In the context of exploring geometrical problems in DGEs leading to explanation and proof, the authors discussed the MD scheme and a DGE proof by contradiction to illustrate the complex interplays between inductive, abductive and deductive reasoning in the transition between empirical and theoretical proof perspectives.

Sinclair and Robutti (2013) surveys research bringing together teaching, learning and proving in DGEs. The survey was done under two related themes: the evolving notion of 'proof' and the epistemological and cognitive nature of dragging and measuring as related in the proving process. The epistemological and cognitive implications of dragging were discussed with respect to the visual-discursive duality that exists for the drag-mode.

The process of forming a drag-based DGE-type proof was illustrated in Leung's (2008a, b) work, where the visualdiscursive duality was explored. Studying and categorizing DGE dragging modalities/strategies have been a core focus attempting to conceptualize proof and explanation in DGE. In connection to this, researchers have begun to attend to the implications on the proving process of measurement in DGEs. The visual-discursive duality becomes even more epistemological and cognitive relevant by the tension created between approximated measurements in DGE and the actually Euclidean measurement. This is the almost-empiricism that Arzarello et al. (2012) referred to where in this case DGE can be regarded as an experimental laboratory with conceptual mathematical objects as objects of investigation. Olivero and Robutti (2007) proposed different categories of DGE measuring modalities (e.g., exploring, guiding, perceptual and proof) 
to study the shift between the spatio-graphic field and the theoretical field. Sinclair and Robutti (2013) went further to describe elementary school and high school case studies to illustrate possible protocols in DGE research around proving. The tasks designed for these cases intended to promote DGE construction exploration, conjecturing and argumentation.

Mariotti (2007) used TSM to address the visual-discursive duality through polyphony of teacher-students mathematical discussion in DGE geometrical construction task. The mediation was illustrated by 'semiotic games' carried out by the teacher and the students during a DGE construction episode. The interpretation game, in which students were asked to predict the next step of action and to compare it with the previous steps, involved a shift in the teacher-students discussion from validating a DGE construction procedure by dragging, to explaining the "the validation by dragging" itself.

Some researchers have considered the relation between DGE-based proofs and traditional ones. For example, in Gravina's (2008) study, two student-generated DGE "dynamical visual proofs" to a non-trivial geometrical construction were presented. These proofs were step-by-step constructions that were translatable into traditional deductive proofs. Leung (2009) proposes that dynamic geometry proofs need not be translated into traditional deductive ones. He reported and analysed a case where a student talked and wrote about his solution to a non-trivial DGE construction problem and produced a written "dynamic geometry proof" for a phenomenon that he observed in his exploration. Such a proof might be evaluated by different standards than those used for traditional written proofs. Baccaglini-Frank et al. (2013) further developed the notion of "pseudo object", to show some DGE-specific features involved in constructing a proof by contradiction. Pseudo objects are a hybrid DGE dynamic figure on which an extra property is mentally project on it by a learner, which may or may not be consistent with Euclidean geometry.

These studies explored the role of DGE as an epistemic tool, in particular dragging, to open up a quasi-empirical dimension to the nature of proof. Regarding DGE as a pedagogical environment where proofs can be elicited, attention should be paid to how DGE affords strategic feedback and mediation, the maintaining of the boundary between mathematical and pedagogical fidelity, transition in the instrumental-semiotic continuum, and the use of discrepancy /uncertainty created (cf. Leung \& Bolite-Frant 2015).

\subsection{Geometry proof in the classroom}

Studies of US geometry textbooks showed that students' opportunities to engage with proof differ based on the textbooks they use and on their teachers' instructional decisions (Sears \& Chávez 2014), and even though there are relatively numerous reasoning-and-proving opportunities in the textbooks, it is still rare for the reasoning-and-proving process itself to be an explicit object of reflection (Otten et al., 2014).

In the Netherlands, Palha et al. (2013) experimented using a shift problem approach to study students' learning process in geometrical proof. A shift problem lesson is "a learning arrangement aiming at fostering a deeper mathematical understanding through problem solving and mathematical discussions in regular classrooms" (p.146). Textbook tasks were locally organized into specific sequence to create opportunities for students to ground their prior knowledge in more concrete realistic experience. The design principles for the shift problem approach were based on the work of Freudenthal and three main proof schemes: empirical proof schemes, external conviction proof schemes, and deductive proof schemes. The findings showed that "regular classroom teachers can work from regular textbooks and give students opportunities to engage in problem solving, creative mathematical thinking and reflection" (p.158).

Leikin and Grossman (2013) studied the teaching of proof using DGE. They explored how teachers modified problems from a standard geometry textbook into investigation problems in DGE in their classes. Different types of problems formulated by the teachers were observed: investigation-oriented problems (teacher-generated discovery and teachergenerated verification types), non-investigation problems (proof, guidance and computational types) and unclear problems. The findings suggested that teachers can develop their understanding of geometry investigation and discovery tasks through the use of DGE and have no difficulty in transforming proof problems into investigation discovery problems. This gives a new direction to teaching geometry proof in the classroom.

Kim and Ju (2012) explored how students changed through learning to construct mathematical proofs in an inquirybased middle school geometry class in Korea. The classroom discourse analysis identified three chronological stages through which students' practice of proof was trans-formed: emergent understanding of proof, proof learning as a goaloriented activity and experiencing proof as the practice of mathematics. The study found that while student learning evolved through these stages from goal-oriented to process-oriented proof learning, the mathematics teacher's role shifted from being an instructor to a mediator of communication.

Abdelfatah (2011) used a story-based dynamic geometry approach asking students to solve daily life situation in DGE through a process of formulating geometric statements, making conjectures, and experiencing proof. The process was 
designed in seven consecutive phases: (1) approaching a real-life situation, (2) experimenting and conjecturing, (3) reformulation conclusions, (4) getting a proof idea, (5) visual explanation, (6) scaffolding proof writing and (7) comparing with the complete proof. The study claimed that story-based DGE was an appropriate cognitive and social constructive learning environment for students to overcome learning difficulties, false beliefs and negative attitudes in a geometry class.

Miyazaki, Fujita and Jones (2015), in a Japanese classroom study on teaching geometrical proof, proposed a proof learning progression called 'flow-chart proving'. Flow-chart proof shows a 'story line' of the proof; connecting the kinds of assumptions from which the conclusion is deduced, the kinds of theorems being used, how the assumptions and conclusion are connected, and so on. It can create 'open' situations where students can construct multiple solutions by deciding their own assumptions and intermediate propositions necessary to deduce a given conclusion. Confronting this logical circularity provided a chance for students to explore their reasoning and to have a deeper understanding of the structure of a geometrical proof.

Another Japanese classroom study by Fujita, Jones and Kunimune (2010) used the lens of cognitive unity (continuity between the process of producing a conjecture and the construction of a proof) to address the tension of between carrying out a challenging geometrical construction and the constructing the related proof. The study showed evidences that cognitive unity was observed in students' arguments when students were able to specify 'data', 'claim' and 'warrant' (Toulmin's model) in their argumentations which led them to more successful proof production.

Yang and Lin (2008) studied reading comprehension of geometry proof (RCGP). This hypothetical RCGP model comprised of five consecutive levels: surface, recognizing elements (pieces), chaining elements (relations) and encapsulation (systems) (ibid, p. 63). These levels were connected by five facets: basic knowledge, logical status and summarization, generality and application. This hypothetical model was reported to be justified by students' performance using a multidimensional scaling method. However, it is still a question whether students' learning trajectory is consistent with this structure.

As mentioned in Sect. 4, Chen and Herbst (2013) explored the interplay among gestures, discourse and diagram in students' geometrical reasoning. They argued that students make use of gestural and verbal expressions to compensate for the limited information given in a diagram as they engage in making and proving conjectures. Students acted on diagrams to create representations for new geometric objects and anticipating geometrical relationships.

\subsection{Concluding comments}

What is and what constitutes a mathematical proof? A mathematical proof is closely tied with the corresponding conjecture or hypothesis, in particular, with how the conjecture or hypothesis came about. Geometrical proof should have perceptual and visual dimensions and due to the advance of social needs and technology, empirical-based elements may play an important epistemic role in proof formation. Thus the nature of proof is fluid reflecting what are needed to convince or explain to someone a geo-metrical phenomenon.

Research done in DGE concerning conjecture formation leading to proof showed the pedagogical significance in toolbased pedagogy to the opening up of a quasi-empirical dimension to the nature of proof. Feedback and mediation from tool may serve as means for boundary crossing between the empirical and theoretical contexts in the proofing process. Pedagogies like tool-based task design, problem solving, inquiry-based learning, mathematical discussion, problem modification, geometrical construction, even gesturing engage students in deep mathematical under-standing leading to conjecture formation processes which may result in alternative meanings of what is a geometrical proof.

\section{Moving beyond traditional Euclidean approaches}

In this section, we first focus on research related to the teaching and learning of 3D geometry, then research on the teaching and learning of non-Euclidean geometries.

\subsection{Focusing on 3D geometry}

A study by Sarfaty and Patkin (2013) found that though second graders were able to correctly identify solids presented to them in 'typical' position, they found it difficult, similar to 2D van Hiele-based research, to identify the same solids in different positions. The arguments given for identification were based on the specific attributes of the solid rather than the perception of the solids in general. The researchers recommend, rather than just introducing learners to concept definitions, that learners be acquainted with a large variety of examples and non-examples of solids in different positions to develop sound concept images of the various solids.

In line with the aforementioned, Ambrose and Kenehan (2009) conducted a teaching experiment with 8- and 9-year olds in which children built and described polyhedra during several lessons. Analysis of pre-/post-assessments showed that 
children advanced in their geometric reasoning and began to identify, enumerate, and notice relation-ships between component parts of polyhedra. A range of examples and non-examples enculturated students into the practice of attending to component parts. Promoting precise, formal definitions for components proved to be a significant challenge for the teacher in establishing norms for class discussions.

Bartolini Bussi (2007) described and illustrated with specific examples some fragments from a teaching experiment on the coordination of spatial perspectives, carried out in several 1st and 2nd grade classrooms over a period of 20 years. Specifically young children's drawing of 3D space was explored. The children first built a 'scene' with some toys, after which they had to describe it and then draw it. This appears to be good preparatory work in figuring out how to describe and draw 3D objects, similar to the 'vision geometry' approach advocated by the Freudenthal Institute, and is important for more formal work with 3D shapes later.

Using two tests administered to students in grades 5 to 9, Pittalis and Christou (2010) identified four distinct types of reasoning which refer to the representation of 3D objects, spatial structuring, conceptualisation of mathematical properties and measurement. This study also showed a strong link between students' spatial abilities, and these four types of reasoning in 3D geometry thinking.

The development and problematization of a task designed to foster spatial visual sense in prospective and practicing elementary and middle school teachers was the focus of a study by Sinclair et al. (2011). They described and analysed the cyclical stages of developing, testing, and modifying several "task drafts" related to ideas around dilation and proportion. The final task incorporated numerous considerations including choices around materials, wording of questions and prompts, and sequencing of experiences. It also reflected their enriched understanding of exploration strategies and the roles of manipulatives and technology in spatial visual tasks designed for adult learners.

Tanguay and Grenier (2010) also explored a teaching experiment with two groups of pre-service mathematics teachers. However, their experiment was aimed at getting them to: (1) define and describe the regular polyhedra, (2) produce them with specific given materials, and (3) prove that the list established is complete. In the first phase, they found that students had difficulty defining polyhedra and specifically conceptualizing the dihedral angle. The proof phase was not conclusive and for the majority of students the quest for regularity and formulae relating sides, edges and vertices overshadowed any other form of reasoning and judgement.

The drag-mode facility in DGEs in three dimensions has become a unique pedagogical tool in recent years that has the potential to facilitate and empower students and teachers to experiment with dynamic geometrical objects, which can lead to the generation of mathematical conjectures. Apart from analysing and modelling task design in such environments generally, Leung (2011) outlines the design of a Cabri 3D activity for exploring the symmetry of solids by virtual manipulation.

Qualitative descriptive studies of pre-service mathematics teachers dragging behaviours with Archimedes Geo 3D and Cabri $3 D$ was carried out by Hatterman (2010). Five different dragging modes were identified, namely, 'free', 'bounded', 'indirect', 'degree of freedom' and 'function test' to describe their observed behaviours.

The design and implementation of a multi-representational approach to explore 3D objects using craft technol-ogy, computer technology, and paper-pencil technology was researched by Camou (2012). Using both qualitative and quantitative research methodology, it was found that students had learned important concepts in 3D geometry and progressed substantially during the two-week experiment. The results of this research culminated in the production of a valuable resource book for teachers by Camou et al (2013) and includes more than one type of representation of 3D objects: (1) solids or lattice models, (2) Cabri 3D or Sketchpad files, and (3) constructions using straight edge and compass or freehand drawings. Their approach also provides an integration of geometry with some algebra and trigonometry.

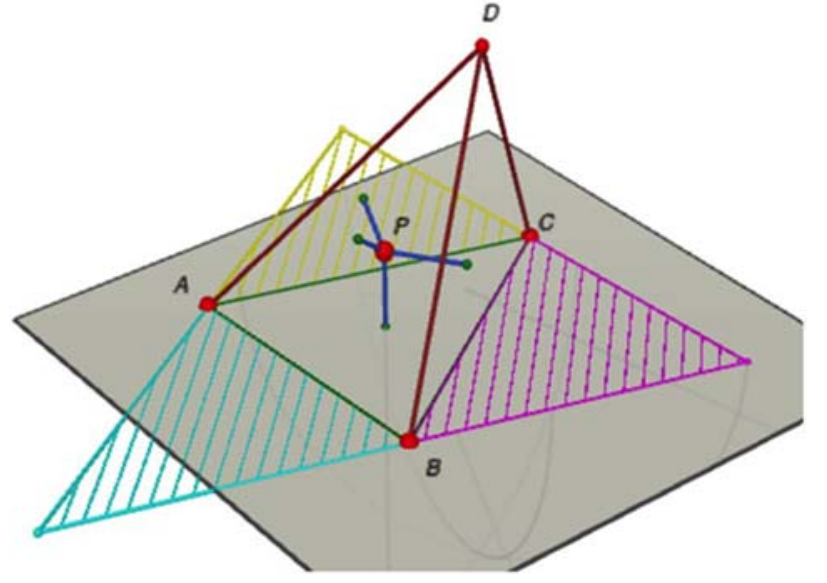

Fig. 3 Generalising Viviani's theory to 3D
An interesting mathematical analogy between quadrilaterals and tetrahedra in relation to certain properties like the centroid, medians, perpendicular bisectors, circumcentre, etc. was explored by Mammana et al. (2009). This analogy was subsequently utilised in Mammana et al. (2012) to develop a set of learning activities, augmented by using the DGE Cabri 3D, to introduce high school students to various aspects of the three dimensional geometry of tetrahedra.

There are numerous other possibilities of extending 2D results to $3 \mathrm{D}$ that can be experimentally investigated in classroom contexts with the aid of software like Cabri-3D, Autograph (V.3) or Geocadabra at high school and university level. For example, Varignon's theorem not only generalises to a non-planar 4-gon in 3D (see Fig. 3), but its generalization to $2 n$-gons is similarly valid for non- planar 
$2 n$-gons in 3D (de Villiers, 2007; Lord, 2008). Using a geometric approach, Vas and Enright (2010) extend and generalise the cross product to higher dimensions in a visual way, and have successfully adapted the approach for non-mathematics majors. Visualisation in all areas of mathematics was strongly promoted in Alsina and Nelsen (2006), and included sections on several ingenious problems in 3D

An interesting mathematical analogy between quadrilaterals and tetrahedra in relation to certain properties like the centroid, medians, perpendicular bisectors, circumcentre, etc. was explored by Mammana et al. (2009). This analogy was subsequently utilised in Mammana et al. (2012) to develop a set of learning activities, augmented by using the DGE Cabri $3 D$, to introduce high school students to various aspects of the three dimensional geometry of tetrahedra.

There are numerous other possibilities of extending 2D results to 3D that can be experimentally investigated in classroom contexts with the aid of software like Cabri-3D, Autograph (V.3) or Geocadabra at high school and university level. For example, Varignon's theorem not only generalises to a non-planar 4-gon in 3D (see Fig. 3), but its generalization to 2ngons is similarly valid for non-planar $2 n$-gons in 3D (de Villiers, 2007; Lord, 2008). Using a geometric approach, Vas and Enright (2010) extend and generalise the cross product to higher dimensions in a visual way, and have successfully adapted the approach for non-mathematics majors. Visualisation in all areas of mathematics was strongly promoted in Alsina and Nelsen (2006), and included sections on several ingenious problems in 3D.

The power of analogy becomes evident in generalizing Viviani's theorem, namely, "the sum of the distances from a point to the sides of an equilateral triangle is constant" to the analogous result in 3D, namely, "the sum of the distances from a point to the faces of a tetrahedron with faces of equal area as shown in Fig. 3 with Cabri 3D" (see de Villiers 2012).

\subsection{Non-Euclidean and other geometries}

Historically the discovery and invention of non-Euclidean geometry was instrumental in fundamentally changing the views of mathematicians (and philosophers) about the nature of axioms. Educationally the question is: Why should our students learn about spherical or other geometries? For many of them, plane geometry is difficult enough to learn - why should we burden them with still another type of geometry? Lénárt (2003) offers the following three reasons, which also apply to the teaching of other geometries such as the taxicab geometry, fractals and higher dimensions:

1. Plane geometry can much more effectively be taught if the learner sees counterexamples of a given concept or theorem.

2. Spherical geometry is extremely useful, because the spherical shape is very frequent in our environment. The most striking example is the Earthglobe on which we live.

3. Learning about different perspectives within mathematics on the concept of a 'circle' or the theorem of Pythagoras, for example, inspires younger and older students to apply this same attitude in other areas of life, toward another person of different social or cultural background, or when getting into another political, economical or technical environment.

Lénárt (2003) advocates a comparative geometry approach; in other words, not teaching other geometries separately from plane geometry, but teaching it alongside. For example, when triangles are first introduced, students explore triangles on the plane as well as on the sphere (or other curved surfaces) using manipulatives, construction tools such as planar and spherical ruler, compass and pro-tractor. It is now also feasible and possible to experimentally explore other geometries using DGEs.

Junius (2008) explored the complex cognitive process involved in learning the concept of 'straightness' in the NonEuclidean geometry of the surface of a sphere from the perspective of a mathematics major student in an upper-level modern geometry class at college. The students' learning of new material was examined through a conflict resolution framework, as the student questioned familiar assumptions understood in Euclidean geometry. This case study revealed how mathematization of the straight line concept in Euclidean and Non-Euclidean geometry emerged through the use of analogy, imagination and motion, moving the student from an extrinsic view to an intrinsic view, thus providing a psychological account of how students might generally learn a new geometry.

Using Easel, Guven and Karatas (2009) explored the actions of a group of prospective mathematics teachers in a dynamic spherical geometry environment. They described how the students made new conjectures using the software, for example, about the sides and angles of a spherical tri-angle, and how the dynamic spherical geometry software assisted them to arrive at proofs; i.e. deductive explanations of their experimental observations.

In a follow-up paper, Guven and Baki (2010) performed an exploratory study, firstly theorising van Hiele levels of understanding for spherical geometry, and secondly, aimed at identifying students' van Hiele levels according to their model. Initially six structured, task-based interviews were held with eight student mathematics teachers at particular times through the course to determine their spherical geometry learning levels. After identifying important properties of spherical geometry levels, the researchers developed an 'Understandings in Spherical Geometry' Test to test whether or not the levels form a hierarchy, and 58 student mathematics teachers took the test. The outcomes of a Guttman scalogram analysis seemed to support their theoretical perspective that there are some levels of understanding in spherical geometry that students progress through in a hierarchical order similar to the Van Hiele levels in Euclidean geometry. 
Using Toulmin's model of argumentation, Hollebrands, Conner and Smith (2010) analyzed college students' argument and warrants within a non-Euclid dynamic geometry context. The task-based interviews with the students focused on examining properties of quadrilaterals in the Poincaré disk model. When students were unsure about a claim, they used the technology as a way of determining whether a stated claim was correct or incorrect. If technology provided confirming evidence, then they generally accepted the claim as true. If the technology provided dis-confirming evidence, then they made a different claim. In some cases, the participants in that study would go on to formally establish the truth of the conclusion, whereas in other cases the participants seemed to be fairly confident in the statement as qualified and would not go on to produce a formal proof. From the interviews, it seemed that when students obtained a result by use of technology, it might have reduced their uncertainty to the point that they no longer saw a need for a formal proof. However, the results generated through use of technology in the argument often did not seem to carry the certainty that a formal proof would have.

A variation of the set of axioms for classical absolute geometry was proposed by Schellenberg (2010), and intended to be accessible to students new to axioms. The metric axioms adopted are the ruler axiom, triangle inequality and the bisector axiom. Angle measure was derived from distance, and all properties needed to establish a consistent system were derived. In particular, the SAS congruence theorem was proved.

The experience of a student using an exploratory artifact of a Turtle geometry model of the hyperbolic surface was discussed in Arzarello et al. (2012). The students; experience was indicative of the value of a digital artefact to offer learners a more concrete and visual situation that can supplement and support traditional proofs, which often appear abstract and lack visual intuition.

Several microworlds of topological surfaces (the Mobius strip, the torus and the Klein bottle) were described by Hawkins and Sinclair (2008), which they created using Sketchpad. They originally designed the microworlds with the intent of providing college students with interactive opportunities to explore topological ideas using a representation that was sufficiently serious, mathematically, to move beyond standard analogies of doughnuts and coffee cups, without being so symbolic or abstract as to discourage elementary intuition and introductory reasoning. However, the constraints and affordances of Sketchpad provoked further mathematical exploration in a new domain that combined both geometric and topological ideas and techniques.

\subsection{Concluding remarks}

There appears to have been little or no research on the teaching and learning of fractals in the past 10 years. This is surprising, given the contemporary interest within mathematics and other fields like physics, chemistry and biology, as well as the ample availability of software to easily display and explore fractals like the Koch curve, Sierpinski gasket, Mandelbrot set, etc. In the past decade, there also seems to have been little or no published research on areas like taxi-cab geometry and higher dimensional geometry.

\section{Conclusion}

The seven themes that we have identified in our survey reflect both traditional research interests in the teaching and learning of geometry as well as new areas of growth. During the past decade, there has been increased focus on embodied and discursive theories in research on the teaching and learning of geometry, with a concomitant research emphasis on visuospatial reasoning (see Sect. 3), on the use of gestures and diagrams (see Sect. 4) and on digital tools (see Sect. 5). Given the importance of visuospatial reasoning in geometry, and in mathematics more broadly, we hope to see more research both on how to provide both teachers and students with more opportunities to engage in visuospatial reasoning and how to find ways to adequately assess and value such reasoning. Such research way well require the use of theoretical frameworks that are capable of integrating discursive and embodied components, as we have argued in Sect. 2.

The effectiveness of certain digital tools, such as DGEs, as well as their increased availability, has also affected researched on topics that span the k-16 geometry curriculum (from early experiences with dynamic triangles to later explorations in spherical geometry) as well as major areas of research such as the proving process (see Sect. 6) and the use and role of definitions (see Sect. 7). While DGEs have been available for over two decades now, several axes of research remain understudied, particular in terms of task design and teacher practice. Given the recent push in many countries to increase computational thinking in the curriculum, an interesting area of study may be to explore how DGEs, as well as other digital tools described in Sect. 5, might offer occasions for coding, particularly when students are asked to model a certain phenomenon using the geometric and numerical primitives of the software.

There has also been a broadening of the traditional scope of geometry, both in terms of cultural perspectives and also in terms of concepts and activities that do not follow the typical Euclidean development-including the Euclidean approach to definitions. We expect to see continued growth in these areas and also hope to see increased research interest in the teaching and learning of geometry since it is a topic whose significance has decreased in many countries because of an 
increased emphasis on number and algebra.

We close with a reflection related to the discipline of mathematics. In the early 1980s, the mathematician Jean Dieudonné.,who in responding to the claim that geometry was no longer a vibrant part of mathematics, wrote:

"[a]nd if anybody speaks of 'the death of Geometry' he [sic] merely testifies to the fact that he [sic] is utterly unaware of $90 \%$ of what mathematicians are doing today" (p. 231).

Indeed, with the work of giants of mathematics such as Grothendieck (a leading figure in the creation of modern algebraic geometry) and Langlands (a key figure in representation theory), mathematics has seen a strong programme of geometrization in which mathematicians engage in studying the deformations of structure that lead to invariants (Zalamea 2012), thus considerably extending Klein's (1872) Erlangen programme (characterising geometries based on transformation groups; Gray 2005). In most countries, the proportion of classroom time spent doing geometry in school mathematics comes nowhere near the $90 \%$ that claimed by Dieudonné for mathematics. While the discipline of mathematics need not prescribe the content of school mathematics, the current enormous discrepancy seems quite surprising and potentially a cause for concern for the mathematics education of the future generation.

\section{References}

Abdelfatah, H. (2011). A story-based dynamic geometry approach to improve attitudes toward geometry and geometric proof. ZDM-The International Journal on Mathematics Education, 43(3), 441-450.

Alsina, C., \& Nelsen, R. B. (2006). Math Made Visual: Creating Images for Understanding Mathematics. Washington: The Mathematical Association of America.

Ambrose, R., \& Kenehan, G. (2009). Children's evolving understanding of polyhedra in the classroom. Mathematical Thinking and Learning, $11(3), 158-176$.

Arici, S., \& Aslan-Tutak, F. (2015). The effect of origami-based instruction on spatial visualization, geometry achievement, and geometric reasoning. International Journal of Science and Mathematics Education, 13(1), 179-200.

Arzarello, F. (2006). Semiosis as a multimodal process. Revista Latinoamericana de Investigación en Matemática Educativa. Special Issue on Semiotics, Culture, and Mathematical Thinking, 9(1), 267-300.

Arzarello, F., Bairral, M. A., \& Danè, C. (2014). Moving from dragging to touchscreen: geometrical learning with geometric dynamic software. Teaching Mathematics and its Applications, 33(1), 39-51.

Arzarello, F., Bartolini Bussi, M. G., Leung, A., Mariotti, M. A., \& Stevenson, I. (2012). Experimental approach to theoretical thinking: Artefacts and proofs. In G. Hanna \& M. de Villers (Eds.), Proof and Proving in Mathematics Education: The 19th ICMI Study (New ICMI Study Series) (pp. 97-137). Berlin: Springer.

Arzarello, F., Olivero, F., Paola, D., \& Robutti, O. (2002). A cognitive analysis of dragging practices in Cabri environments. ZDM, 34(3), 66-72.

Atebe, H. U., \& Schäfer, M. (2008). "As soon as the four sides are all equal, then the angles must be $90^{\circ}$ ”. Children's misconceptions in geometry. African Journal of Research in Science, Mathematics and Technology Education, 12(2), 47-66.

Atebe, H. U., \& Schäfer, M. (2011). The nature of geometry instruction and observed learning-outcomes opportunities in Nigerian and South African high schools. African Journal of Research in Mathematics, Science and Technology Education, 15(2), 191-204.

Baccaglini-Frank, A. (2011). Abduction in generating conjectures in dynamic geometry through maintaining dragging. In M. Pytlak, T. Rowland, $\&$ E. Swoboda (Eds.), Proceedings of the Seventh Congress of the European Society for Research in Mathematics Education (pp. 110-119). Poland: Rzeszów.

Baccaglini-Frank, A., Antonini, S., Leung, A., \& Mariotti, M. A. (2013). Reasoning by contradiction in dynamic geometry. PNA, 7(2), 63-73.

Baccaglini-Frank, A., \& Mariotti, M. A. (2010). Generating conjectures in dynamic geometry: the maintaining dragging model. International Journal of Computers for Mathematical Learning, 15(3), 225-253.

Balacheff, N. (2013). cKф, a model to reason on learners' conceptions. In M. V. Martinez \& A. C. Superfine (Eds.), Proceedings of the 35th annual meeting of the North American Chapter of the International Group for the Psychology of Mathematics Education (pp. 2-15). IL, United States: Chicago.

Balacheff, N., \& Margolinas, C. (2005). cKф Modèle des connaissances pour le calcul de situation didactiques. In A. Mercier \& C. Margolinas (Eds.), Balises pour la didactique des mathématiques (pp. 75-106). Grenoble: La Pensée Sauvage.

Barany, M., \& MacKenzie, D. (2014). Chalk: Materials and concepts in mathematics research. In C. Coopmans, J. Vertesi, M. Lynch, \& S. Woolgar (Eds.), Representation in scientific practice revisited (pp. 107-130). Cambridge: The MIT Press.

Bartolini Bussi, M. G. (2007). Semiotic mediation: fragments from a classroom experiment on the coordination of spatial perspectives. ZDMThe International Journal on Mathematics Education, 39(1), 63-71.

Bartolini Bussi, M. G. (2010). Historical artefacts, semiotic mediation and teaching proof. In G. Hanna, et al. (Eds.), Explanation and proof in mathematics: philosophical and educational perspectives (pp. 151-167). New York: Springer.

Bartolini Bussi, M. G., \& Baccaglini-Frank, A. (2015). Geometry in early years: sowing the seeds towards a mathematical definition of squares and rectangles. ZDM Mathematics Education, 47(3), 391-405.

Bartolini Bussi, M. G., \& Mariotti, M. A. (2008). Semiotic mediation in the mathematics classroom: artefacts and signs after a Vygotskian perspective. In: L. English, M. Bartolini Bussi, G. Jones, R. Lesh, \& D. Tirosh (Eds.), Handbook of international research in mathematics education (pp. 720-749, 2nd éd.). Mahwah: Erlbaum.

Bartolini Bussi, M. G., Taimina, D., \& Isoda, M. (2010). Concrete models and dynamic instruments as early technology tools in classrooms at the dawn of ICMI: from Felix Klein to present applications in mathematics classrooms in different parts of the world. ZDM-The International Journal on Mathematics Edu-cation, 42(1), 19-31.

Baulac, Y., Bellemain, F., \& Laborde, J. M. (1988). Cabri-géomètre, un logiciel d'aide à l'enseignement de la géométrie, logiciel et manuel d'utilisation, Paris: Cedic-Nathan

Bautista, A., \& Roth, W.-M. (2012). Conceptualizing sound as a form of incarnate mathematical consciousness. Educational Studies in Mathematics, 79(1), 1-19. 
Bonnard, Q., Verma, H., Kaplan, F., \& Dillenbourg, P. (2012). Paper interfaces for learning geometry. In: A. Ravenscroft, S. Lindstaedt, C. Kloos, and D. Hernández-Leo (eds.) 21st Century Learning for 21st Century Skills; Lecture Notes in Computer Science (vol 7563; pp. 37-50). Berlin: Springer.

Bryant, P. (2008). Paper 5: understanding spaces and its representation in mathematics. In: T. Nunez, P. Bryant, \& A. Watson (Eds.), Key understanding in mathematics learning: a report to the Nuffield foundation. Retrieved from http://www.nuffieldfoundation.org/sites/default/files/P5.pdf

Bu, L., \& Haciomeroglu, E. S. (2010). Sliders in dynamic mathematics learning environments: their pedagogical roles. Mathematics and Computer Education, 44(3), 213-221.

Burgmanis, G̣., Krišjāne, Z., \& Šķilters, J. (2014). Acquisition of spatial knowledge in different urban areas: evidence from a survey analysis of adolescents. International Quarterly of Cognitive Science, 15(3), 373-383.

Camou, B.J. (2012). High school students' learning of 3D geometry using iMAT (integrating Multitype-representations, Approximations and Technology) engineering. (Doctoral dissertation), University of Georgia.

Camou, B., Olive, J., Colucci, M., \& Garcia, G. (2013). Essential 3D geometry. San Diego: University Readers.

Casey, B. M., Andrews, N., Schindler, H., Kersh, J. E., Samper, A., \& Copley, J. (2008). The development of spatial skills through interventions involving block-building activities. Cognition and Instruction, 26(3), 269-309.

Chang, K. E., Wu, L. J., Lai, S. C., \& Sung, Y. T. (2014). Using mobile devices to enhance the interactive learning for spatial geometry. Interactive Learning Environments, 23(1), 1-19.

Chen, C.-L., \& Herbst, P. (2013). The interplay among gestures, discourse, and diagrams in students' geometrical reasoning. Educational Studies in Mathematics, 83(2), 285-307.

Cheng, K., Huttenlocher, J., \& Newcombe, N. (2013). 25 years of research on the use of geometry in spatial reorientation: a cur-rent theoretical perspective. Psychonomic Bulletin and Review, 20(6), 1033-1054.

Cheng, Y.-L., \& Mix, K. (2014). Spatial training improves children's mathematics ability. Journal of Cognition and Development, $15(1), 2-11$.

Choi, K., \& Oh, S. Kyoung. (2008). Teachers' conceptual errors related to the definitions in the area of geometry of elementary school mathematics. Journal of the Korean Society of Mathematical Education. Series A. The Mathematical Education, 47(2), 197-219.

Choi, S. I., \& Kim, S. J. (2013). A study on students' understanding of figures through descriptive assessment. East Asian Mathematical Journal, 29(2), 207-239.

CindyJS Project (2015). CindyJS: A JavaScript framework for inter-active (mathematical) content, http://cindyjs.org. Accessed 20 June 2016.

Clements, M. (2012). A historical overview of visualisation and visualising in mathematics education. Israel: Paper presented at the Retirement Symposium of Ted Eisenberg.

Clements, D. H., Sarama, J., Spitler, M. E., Lange, A. A., \& Wolfe, C. B. (2011). Mathematics learned by young children in an intervention based on learning trajectories: a large-scale cluster randomized trial. Journal for Research in Mathematics Education, 42(2), $127-166$.

David, M., \& Tomaz, V. (2012). The role of visual representations for structuring classroom mathematical activity. Educational Studies in Mathematics, 80(3), 413-431.

Davis, B., \& Spatial Reasoning Study Group. (2015). Spatial reasoning in the early years: Principles, assertions, and speculations. New York: Routledge.

de Freitas, E., \& Sinclair, N. (2012). Diagram, gesture, agency: theorizing embodiment in the mathematics classroom. Educational Studies in Mathematics, 80(1), 133-152.

de Villiers, M. (1994). The role and function of a hierarchical classification of quadrilaterals. For the Learning of Mathematics, 14(1), 11-18.

de Villiers, M. (2007). A hexagon result and its generalization via proof. The Montana Mathematics Enthusiast, 4(2), $188-192$.

de Villiers, M. (2004). Using dynamic geometry to expand mathematics teachers' understanding of proof. The International Journal of Mathematical Education in Science and Technology, 35(5), 703-724.

de Villiers, M. (2011). Simply symmetric. Learning and Teaching Mathematics, 11, 22-26.

de Villiers, M. (2012). Generalizing a problem of Sylvester. The Mathematical Gazette, 96(535), 78-81.

de Villiers, M., Govender, R., \& Patterson, N. (2009). Defining in Geometry. In T. Craine \& R. Rubinstein (Eds.), Seventy-first NCTM Yearbook: Understanding Geometry for a Changing World (pp. 189-203). Reston: NCTM.

Ding, L., Jones, K., \& Zhang, D. (2015). Teaching geometrical theorems in grade 8 using the 'Shen Tou' method: a case study in Shanghai. In: L. Fan, N-Y. Wong, J. Cai \& S. Li (Eds.), How Chinese teach mathematics: perspectives from insiders (pp. 279-312). Singapore: World Scientific.

Doyle, R. A., Voyer, D., \& Cherney, I. D. (2012). The relation between childhood spatial activities and spatial abilities in adulthood. Journal of Applied Developmental Psychology, 33(2), 112-120.

Duatepe-Paksu, A., \& Ubuz, B. (2009). Effects of drama-based geometry instruction on student achievement, attitudes, and thinking levels. The journal of Educational Research, 102(4), 272-285.

Duval, R. (1998). Geometry from a cognitive point of view. In C. Mammana \& V. Villani (Eds.), Perspectives on the teaching of geometry for the 21st Century: an ICMI study (pp. 37-52). Dordrecht: Kluwer.

Duval, R. (2005). Les conditions cognitives de l'apparentissage de la géométrie: Développement de la visualisation, differenciation des raisonnement et coordination de leurs fonctionnements Annales de didactique et sciences cognitives, 10, 5-53.

Ehmann, M., Gerhauser, M., Miller, C., \& Wassermann, A. (2013). Sketchometry and jsxgraph: dynamic geometry for mobile devices. South Bohemia Mathematical Letters, 21(1), 1-7.

Erdogan, E. O., \& Dur, Z. (2014). Preservice mathematics teachers' personal figural concepts and classifications about quadrilaterals. Australian Journal of Teacher Education, 39(6), 107-133.

Erez, M., \& Yerushalmy, M. (2006). "If you can turn a rectangle into a square, you can turn a square into a rectangle": young students' experience the dragging tool. International Journal of Computers for Mathematical Learning, 11(3), 271-299.

Fahlgren, M., \& Brunström, M. A. (2014). A model for task design with focus on exploration, explanation, and generalization in a dynamic geometry environment. Technology, Knowledge and Learning, 19(3), 1-29.

Fischbein, E. (1993). The theory of figural concepts. Educational studies in mathematics, 24(2), 139-162.

Forsythe, S. K. (2015). Dragging maintaining symmetry: can it generate the concept of inclusivity as well as a family of shapes? Research in Mathematics Education, 17(3), 198-219.

Foster, C. (2014). Being inclusive. Mathematics in School, 43(3), 12-13.

Freudenthal, H. (1973). Mathematics as an Educational Task. Dordrecht: Reidel. 
Fujita, T. (2012). Learners' level of understanding of the inclusion relations of quadrilaterals and prototype phenomenon. Journal of Mathematical Behavior, 31(1), 60-72.

Fujita, T., \& Jones, K. (2007). Learners' understanding of the definitions and hierarchical classification of quadrilaterals: towards a theoretical framing. Research in Mathematics Education, 9(1\&2), 3-20.

Fujita, T., Jones, K., \& Kunimune, S. (2010). Student's geometrical constructions and proving activities: a case of cognitive unity? In: Pinto, MF., \& Kawasaki, T. F., (Eds.), Proceedings of the 34th International Conference of PME (Vol. 3, pp. 9-16). Belo Horizonte, Brazil.

Fyhn, A. (2008). A climbing class' reinvention of angles. Educational Studies in Mathematics, 67(1), 19-35.

Gal, H., \& Lew, H. C. (2008). Is a rectangle a parallelogram? Towards a bypass of Van Hiele Level 3 decision making. In H. N. Jahnke \& H.-C. Lew (Eds.), The 11th International Congress on Mathematical Education. Mexico: Monterrey.

Gal, H., \& Linchevski, L. (2010). To see or not to see: analyzing difficulties in geometry from the perspective of visual perception.

Educational Studies in Mathematics, 74(2), 163-183.

Gerhäuser, M., Valentin, B., \& Wassermann, A. (2010). JSXGraph: dynamic Mathematics with JavaScript. International Journal for Technology in Mathematics Education, 17(4), 211-215.

Giofrè, D., Mammarella, I. C., Ronconi, L., \& Cornoldi, C. (2013). Visuospatial working memory in intuitive geometry, and in academic achievement in geometry. Learning and Individual Differences, 23, 114-122.

Gol Tabaghi, S., \& Sinclair, N. (2013). Using dynamic geometry software to explore eigenvectors: the emergence of dynamic-synthetic-geometric thinking. Technology, Knowledge and Learning, 18(3), 149-164.

Goldin-Meadow, S. (2003). Hearing gesture: How our hands help us think. Cambridge: Belknap, Harvard University Press.

Gómez-Chacón, I. M., \& Kuzniak, A. (2015). Spaces for geometric work: figural, instrumental, and discursive geneses of reasoning in a technological environment. International Journal of Science and Mathematics Education, 13(1), 201-226.

González, G., \& Herbst, P. (2009). Students' conceptions of congruency through the use of dynamic geometry software. International Journal of Computers for Mathematical Learning, 14(2), 153-182.

Govender, R., \& De Villiers, M. (2004). A dynamic approach to quadrilateral definitions. Pythagoras, 58, 34-45.

Gravina, M. A. (2008). Drawing in movement and insights for the proof process. International Journal of Continuing Engineering Education and Life-Long Learning, 18(5/6), 564-574.

Gray, J. (2005). Felix Klein's Erlangen Program, 'Comparative con-siderations of recent geometrical researches' (1872). In I. Grattan-Guiness (Ed.), Landmark Writings in Western Mathematics, 1640-1940 (pp. 544-552). Amsterdam: Elsevier.

Gu, L. (1992). The Qingpu experience. Paper presented at the 7th International Congress of Mathematical Education, Quebec.

Gu, L., Huang, R., \& Marton, F. (2004). Teaching with variation: An effective way of mathematics teaching in China. In L. Fan, N. Y. Wong, J. Cai, \& S. Li (Eds.), How Chinese learn mathematics: perspectives from insiders (pp. 309-345). Singapore: World Scientific.

Güçler, B., Hegedus, S., Robidoux, R., \& Jackiw, N. (2013). Investigating the mathematical discourse of young learners involved in multi-modal mathematical investigations: the case of haptic technologies. In D. Martinovic, V. Freiman, \& Z. Karadag (Eds.), Visual mathematics and cyberlearning (pp. 97-118). Berlin: Springer.

Gutiérrez, A., Jaime, A., \& Fortuny, J. M. (1991). An alternative paradigm to evaluate the acquisition of the van Hiele levels. Journal for Research in Mathematics Education, 22(3), 237-251.

Guven, B., \& Baki, A. (2010). Characterizing student mathematics teachers' levels of understanding in spherical geometry. International Journal of Mathematical Education in Science and Technology, 41(8), 991-1013.

Guven, B., \& Karatas, I. (2009). Students discovering spherical geometry using dynamic geometry software. International Journal of Mathematical Education in Science and Technology, 40(3), 331-340.

Hare, A. \& Sinclair, N. (2015). Pointing in an undergraduate abstract algebra lecture: interface between speaking and writing. Proceedings of the 39th Conference of the International Group for the Psychology of Mathematics Education, Australia: Hobart.

Haßler, B., Hennessy, S., Cross, A., Chileshe, E., \& Machiko, B. (2014). School-based professional development in a developing context: lessons learnt from a case study in Zambia. Professional Development in Education, pp 1-20.

Hatterman, M. (2010). A first application of new theoretical terms on observed dragging modalities in 3D Dynamic Geometry Environments. In: Pinto, M. F., \& Kawasaki, T. F., (Eds.), Proceedings of the 34th Conference of the International Group for the Psychology of Mathematics Education (Vol. 3, pp. 57-64), Brazil.

Hawkins, A., \& Sinclair, N. (2008). Explorations with Sketchpad in topogeometry. International Journal of Computers for Mathematical Learning, 13(1), 71-82.

Healy, L., \& Fernandes, S. H. A. A. (2011). The role of gestures in the mathematical practices of those who do not see with their eyes. Educational Studies in Mathematics, 77(2), 157-174.

Healy, L., \& Powell, A. (2013). Understanding and overcoming "disadvantage" in learning mathematics. In: M. Clements, A. Bishop, C. Keitel, J. Kilpatrick, \& F. Leung (Eds.), Third international handbook of mathematics education. New York: Springer.

Hegedus, S. J., \& Moreno-Armella, L. (2010). Accommodating the instrumental genesis framework within dynamic technological environments For the Learning of Mathematics, 30(1), 26-31.

Hershkowitz, R. (1990). Psychological aspects of learning geometry. In P. Nesher \& J. Kilpatrick (Eds.), Mathematics and cognition (pp. 70-95). Cambridge: Cambridge University Press.

Hodge, A., \& Frick, K. (2009). University preparation of pre-service secondary geometry teachers: a need for research. Journal of Mathematical Sciences and Mathematics Education, 4(1), 28-36.

Hollebrands, K. F. (2007). The role of a dynamic software program for geometry in the strategies high school mathematics students employ. Journal for Research in Mathematics Education, 38(2), 164-192.

Hollebrands, K. F., Conner, A., \& Smith, R. C. (2010). The nature of arguments provided by college geometry students with access to technology while solving problems. Journal for Research in Mathematics Education, 41(4), 324-350.

Hung, P. H., Hwang, G. J., Lee, Y. H., \& Su, I. (2012). A cognitive component analysis approach for developing game-based spatial learning tools. Computers \& Education, 59(2), 762-773.

Iijama, Y. (2012). GC/HTML5: dynamic geometry software which can be used with Ipad and PC - feature of software and some lessons with it. In: The proceedings of the 12th International Congress on Mathematical Education. COEX, Seoul, Korea.

Ingraham, M. (2013). Incorporating iPad technology into the classroom: a geometry project. Ohio Journal of School Mathematics, 2013(67), 2732.

Isotani, S., Pedro, L. Z., Reis, H. M., Borges, S. S., Lopes, A. M., Souza, J., Brandão, A. F. \& Brandão, L. O. (2014). Interactive geometry goes 
mobile with GeoTouch. In: 2014 IEEE 14th international conference on advanced learning technologies (ICALT) (pp. 181-185). Sao Paulo, Brazil.

Jackiw, N. (1989). The Geometer's Sketchpad (Computer Software). Berkeley: Key Curriculum Press.

Jackiw, N. (2013). Touch and multitouch in dynamic geometry: Sketchpad explorer and "digital" mathematics. In E. Faggiano \& A. Montone (Eds.), Proceedings of the 11th International Conference on Technology in Mathematics Teaching (pp. 149-155). Italy: Bari.

Jackiw, N., \& Sinclair, N. (2009). Sounds and pictures: dynamism and dualism in dynamic geometry. ZDM-The International Journal on Mathematics Education, 41(4), 413-426.

Jahnke, H. N., \& Wamback, R. (2013). Understanding what a proof is: a classroom-approach. ZDM-The International Journal on Mathematics Education, 45(3), 469-482.

Jawahir, R. (2013). Effective learning and teaching strategies of two-dimensional geometry at the upper primary grades in Mauritius. (PhD), University of Technology, Mauritius.

Jirout, J., \& Newcombe, N. (2015). Building blocks for developing spatial skills: evidence from a large, representative U.S. sample. Psychological Science, $26(3), 302-310$.

Jo, I., \& Bednarz, S. (2014). Dispositions toward teaching spatial thinking through geography: conceptualization and an exemplar assessment. Journal of Geography, 113(5), 198-207.

Jones, K., \& Fujita, T. (2013). Characterising triangle congruency in lower secondary school: the case of Japan. In B. Ubuz, Ç. Haser, \& M. A. Mariotti (Eds.), Proceedings of the 8th Congress of the European Society for Research in Mathematics Education (pp. 655-664). Turkey: Antalya.

Jones, K., \& Herbst, P. (2011). Proof, proving, and teacher-student interaction: theories and contexts. In G. Hanna \& M. de Villiers (Eds.), Proof and proving in mathematics education: the 19th ICMI study (pp. 261-277). Berlin: Springer.

Jones, K., Mackrell, K., \& Stevenson, I. (2010). Designing digital technologies and learning activities for different geometries. In: C. Hoyles \& J.-B. Lagrange (Eds.), Mathematics education and technology: rethinking the terrain. The 17th ICMI study (pp. 47-60). New York: Springer.

Junius, P. (2008). A case example of insect gymnastics: how is non-Euclidean geometry learned? International Journal of Mathematical Education in Science and Technology, 39(8), 987-1002.

Kaur, H. (2015). Two aspects of young children's thinking about different types of dynamic triangles: prototypicality and inclusion. ZDM Mathematics Education, 47(3), 407-420.

Kim, D., \& Ju, M. (2012). A changing trajectory of proof learning in the geometry inquiry classroom. ZDM-The International Journal on Mathematics Education, 44(2), 149-160.

Kim, M., Roth, W.-M., \& Thom, J. (2011). Children's gestures and the embodied knowledge of geometry. International Journal of Science and Mathematics Education, 9(1), 207-238.

Klein, F. (1872). Vergleichende Betrachtungen über neuere geometrische Forschungen (Das Erlanger Programm). Erlangen: A. Deichert.

Kortenkamp, U., \& Dohrmann, C. (2010). User interface design for dynamic geometry software. Acta Didactica Napocensia, 3(2), 59-66.

Kuzniak, A. (2014). Understanding the nature of the geometric work through its development and its transformation. In: S. Rezat, M. Hattermann, \& A. Peter-Koop (Eds.), Transformation: a fundamental idea of mathematics education (pp. 311-325). New York: Springer.

Laborde, C., \& Laborde, J.-M. (2014). Dynamic and tangible representations in mathematics education. In S. Rezat, M. Hattermann, \& A. Peter-Koop (Eds.), Transformation: A Fundamental Idea of Mathematics Education (pp. 187-202). New York: Springer.

Lai, K., \& White, T. (2014). How groups cooperate in a networked geometry learning environment. Instructional Science, 42(4), $615-637$.

Lakoff, G., \& Núñez, R. (2000). Where mathematics comes from: How the embodied mind brings mathematics into being. New York: Basic Books.

Latsi, M., \& Kynigos, C. (2012). Experiencing 3D simulated space through different perspectives. In A. Jimoyiannis (Ed.), Research on e-Learning and ICT in Education: Technological, Pedagogical and Instructional Issues (pp. 183-196). Berlin: Springer.

Lord, N. (2008). Maths bite: Averaging polygons. The Mathematical Gazette, 92(523), 134.

Lavicza, Z., Hohenwarter, M., Jones, K., Lu, A., \& Dawes, M. (2010). Establishing a professional development network around dynamic mathematics software in England. International Journal for Technology in Mathematics Education, 17(4), 177-182.

Lee, C. Y., \& Chen, M. J. (2014). The impacts of virtual manipulatives and prior knowledge on geometry learning performance in junior high school. Journal of Educational Computing Research, 50(2), 179-201.

Lee, S. A., Sovrano, V. A., \& Spelke, E. S. (2012). Navigation as a source of geometric knowledge: young children's use of length, angle, distance, and direction in a reorientation task. Cognition, 123(1), 144-161.

Lehrer, R., Jenkins, M., \& Osana, H. (1998). Longitudinal study of children's reasoning about space and geometry. In R. Lehrer \& D. Chazan (Eds.), Designing learning environments for developing understanding of geometry and space (pp. 137-167). Mahwah: Erlbaum.

Leikin, R., \& Grossman, D. (2013). Teachers modify geometry problems: from poof to investigation. Educational Studies in Mathematics, 82(3), $515-531$.

Lénárt, I. (2003). Non-Euclidean adventures on the Lénárt sphere. Emeryville: Key Curriculum Press.

Leung, A. (2008a). Dragging in a dynamic geometry environment through the lens of variation. International Journal of Computers for Mathematical Learning, 13(2), 135-157.

Leung, I. K. C. (2008b). Teaching and learning of inclusive and transitive properties among quadrilaterals by deductive reasoning with the aid of SmartBoard. ZDM - The International Journal on Mathematics Education, 40(6), 1007-1021.

Leung, A. (2009). Written proof in dynamic geometry environment: inspiration from a student's work. In: Lin, F-L., Hsieh, F-J., Hanna, G., \& De Viller, M. (Eds.). Proceedings of the ICMI 19 study conference: proof and proving in mathematics education (vol. 2, pp. 15-20). Taipei, Taiwan.

Leung, A. (2011). An epistemic model of task design in dynamic geometry environment. ZDM-The International Journal on Mathematics Education, 43(3), 325-336.

Leung, A. (2012). Variation and mathematics pedagogy. In J. Dindyal, L. P. Cheng, \& S. F. Ng (Eds.), Mathematics education: Expanding horizons: Proceedings of the 35th annual conference of the Mathematics Education Research Group of Australasia (Vol. 2, pp. 435-442). Singapore: MERGA Inc.

Leung, A., Baccaglini-Frank, A., \& Mariotti, M. A. (2013). Discernment in dynamic geometry environments. Educational Studies in Mathematics, 
84(3), 439-460.

Leung, A., \& Bolite-Frant, J. (2015). Designing mathematics tasks: the role of tools. In A. Watson \& M. Ohtani (Eds.), Task Design in Mathematics Education: The 22nd ICMI Study (New ICMI Study Series) (pp. 191-225). New York: Springer.

Leung, A., \& Lee, A. M. S. (2013). Students' geometrical perception on a task-based dynamic geometry platform. Educational Studies in Mathematics, 82(3), 361-377.

Levenson, E., Tirosh, D., \& Tsamir, P. (2011). Preschool geometry. Theory, research, and practical perspectives. Rotterdam: Sense Publishers.

Lowrie, T., Logan, T., \& Scriven, B. (2012). Perspectives on geometry and measurement in the Australian curriculum: mathematics. In: B. Atweh, M. Goos, R. Jorgensen, \& D. Siemon (Eds.), Engaging the Australian National Curriculum: mathematics—perspectives from the field. (pp. 71-88). Adelaide: Australia: Mathematics Education Research Group of Australasia.

Luitel, B. C. (2009). Culture, worldview and transformative philoso-phy of mathematics education in Nepal: a cultural-philosophical inquiry. Curtin, Perth.

Luitel, B. C. (2013). Mathematics as an im/pure knowledge system, symbiosis, (w)holism and synergy in mathematics education., International Journal of Science and Mathematics Education, 11, 65-87.

Mackrell, K. (2011). Design decisions in interactive geometry software. ZDM -The International Journal on Mathematics Education, 43(3), 373387.

Mainali, B. R. (2008). Comparison of traditional teaching and learning of reflection and rotation in a Nepalese high school with an ICT-rich, student-centered, guided discovery approach (Masters), University of Amsterdam, Amsterdam, The Netherlands. Retrieved from http://www.scriptiesonline.uba.uva.nl/. Accessed 17 June 2016.

Mainali, B. R., \& Key, M. B. (2012). Using dynamic geometry software GeoGebra in developing countries: A case study of impressions of mathematics teachers in Nepal. International Journal for Mathematics Teaching and Learning, 12, 1-21.

Mammana, M. F., Micale, B., \& Pennisi, M. (2009). Quadrilaterals and tetrahedra. International Journal of Mathematical Education in Science and Technology, 40(6), 817-828.

Mammana, M. F., Micale, B., \& Pennisi, M. (2012). Analogy and dynamic geometry system used to introduce three-dimensional geometry. International Journal of Mathematical Education in Science and Technology, 43(6), 818-830.

Mammarella, I., Giofrè, D., Ferrara, R., \& Cornoldi, C. (2013). Intuitive geometry and visuospatial working memory in children showing symptoms of nonverbal learning disabilities. Child Neuropsychology, 19(3), 235-249.

Mariotti, M. A. (2007). Geometrical proof: the mediation of a microworld. In P. Boero (Ed.), Theorems in School: From History, Epistemology, and Cognition to Classroom Practice (pp. 285-304). Rotterdam: Sense Publishers.

Mariotti, M. A. (2014). Transforming images in a DGS: The semiotic potential of the dragging tool for introducing the notion of conditional statement. In S. Rezat, M. Hattermann, \& A. Peter-Koop (Eds.), Transformation-A Fundamental Idea of Mathematics Education (pp. 155172). New York: Springer.

Mariotti, M. A., \& Fischbein, E. (1997). Defining in classroom activities. Educational Studies in Mathematics, 34, $219-248$.

Markovic, Z., \& Romano, D. A. (2013). Gaining insight of how elementary school students conceptualize geometric shape of parallelogram. Open Mathematical Education Notes, 3, 31-41.

Marton, F., Runesson, U., \& Tsui, A. B. M. (2004). The space of learning. In F. Marton \& A. B. M. Tsui (Eds.), Classroom discourse and the space of learning (pp. 3-40). Mahwah: Lawrence Erlbaum Associates.

Maschietto, M., \& Bartolini Bussi, M. G. (2009). Working with artefacts: gestures, drawings and speech in the construction of the mathematical meaning of the visual pyramid. Educational Studies in Mathematics, 70(2), 143-157.

Massarwe, K., Verner, I., \& Bshouty, D. (2010). Pathways of creativity: Joyful learning of geometry through analysis and construction of ornaments. Mediterranean Journal for Research in Mathematics Education. Special Issue Intercultural Aspects of Creativity: Challenges and Barriers, 9(2), 93-105.

Menz, P. (2015). Unfolding of Diagramming and Gesturing between Mathematics Graduate Student and Supervisor during Research Meetings. Ph.D dissertation, Department of Mathematics, Simon Fraser University.

Miyazaki, M., Fujita, T., \& Jones, K. (2015). Flow-chart proofs with open problems as scaffolds for learning about geometrical proof. ZDM Mathematics Education, 47(7), 1211-1224.

Morgan, C., \& Alshwaikh, J. (2012). Communicating experience of 3D space: mathematical and everyday discourse. Mathematical Thinking and Learning, 14(3), 199-225.

Moutsios-Rentzos, A., \& Spyrou, P. (2013). The need for proof in geometry: a theoretical investigation through Husserl's phenomenology. In: Lindmeier, A. M. \& Heinze, A. (Eds.), Proceedings of the 37th Conference of the International Group for the Psychology of Mathematics Education (Vol. 3, pp. 329-336). Kiel, Germany.

Neel-Romine, L. E., Paul, S., \& Shafer, K. G. (2012). Get to know a circle. Mathematics Teaching in the Middle School, 18(4), 222- 227. doi: 10.5951/mathteacmiddscho.18.4.0222

Newcombe, N., \& Stieff, M. (2012). Six myths about spatial thinking. International Journal of Science Education, 34(6), 955-971.

Newton, J. (2010). An examination of K-8 geometry state standards through the lens of van Hiele levels of geometric thinking. In J. P. Smith (Ed.), Variability is the rule: a companion analysis of K-8 state mathematics standards (pp. 71-94). Charlotte: InfoAge Publishing.

Ng, O., \& Sinclair, N. (2015a). Young children reasoning about symmetry in a dynamic geometry environment. ZDM Mathematics Education, $47(3), 421-434$.

Ng, O., \& Sinclair, N. (2015b). “Area without numbers": using touch-screen dynamic geometry to reason about shape. Canadian Journal of Science, Mathematics and Technology Education, 15(1), 84-101.

Okazaki, M. (2009). Process and means of reinterpreting tacit properties in understanding the inclusion relations between quadrilaterals. In: Tzekaki, M., Kaldrimidou, M., \& Sakonidis, C., (Eds.), Proceedings of the 33rd conference of the International Group for the Psychology of Mathematics Education (Vol. 4, pp. 249-256). Thessaloniki, Greece.

Okazaki, M. (2013). Identifying situations for fifth graders to construct definitions as conditions for determining geometric figures. In: Proceedings of the 37th conference of the international group for the psychology of mathematics education (Vol. 3, pp. 409-416). Kiel, Germany.

Okazaki, M., \& Fujita, T. (2007). Prototype phenomena and common cognitive paths in the understanding of the inclusion relations between quadrilaterals in Japan and Scotland. In J. H. Woo, H. C. Lew, K. S. Park, \& D. Y. Seo (Eds.), Proceedings of the 31st Conference of the International Group for the Psychology of Mathematics Education (Vol. 4, pp. 41-48). Seoul: Seoul National University.

Olivero, F., \& Robutti, O. (2007). Measuring in dynamic geometry environments as a tool for conjecturing and proving. International Journal of Computers for Mathematical Learning, 12(2), 135-156. 
Otten, S., Gilbertson, N. J., Males, L. M., \& Clark, D. L. (2014). The mathematical nature of reasoning-and-proving opportunities in geometry textbooks. Mathematical Thinking and Learning, 16(1), 51-79.

Owens, K. (2004). Improving the teaching and learning of space mathematics. In B. Clarke, D. Clarke, G. Emanuelsson, B. Johansson, D. Lambdin, F. Lester, A. Wallby, \& K. Wallby (Eds.), International perspectives on learning and teaching mathematics (pp. 569-584). Gothenburg: Göteborg University National Center for Mathematics Education.

Owens, K. (2014). Diversifying our perspectives on mathematics about space and geometry: an ecocultural approach. International Journal of Science and Mathematics Education, 12(4), 941-974.

Owens, K. (2015). Visuospatial reasoning: An ecocultural perspective for space, geometry and measurement education. New York: Springer.

Owens, K., Cherinda, M., \& Jawahir, R. (2015). The importance of an ecocultural perspective for Indigenous and transcultural education. In K. Owens (Ed.), Visuospatial reasoning: An ecocultural perspective for space, geometry and measurement education (pp. 245-273). New York: Springer.

Owens, K., \& Highfield, K. (2015). Visuospatial reasoning in contexts with digital technology. In K. Owens (Ed.), Visuospatial reasoning (pp. 275-289). Berlin: Springer.

Owens, K., McPhail, D., \& Reddacliff, C. (2003). Facilitating the teaching of space mathematics: An evaluation. In N. Pateman, B. Dougherty, \& J. Zilliox (Eds.), Proceedings of 27th annual conference of the International Group for the Psychology of Mathematics Education (Vol. 1, pp. 339-345). Hawaii: International Group for the Psychology of Mathematics Education.

Palha, S., Dekker, R., Gravemeijer, K., \& Van Hout-Wolters, B. (2013). Developing shift problems to foster geometrical proof and understanding. Journal of Mathematical Behavior, 32(2), 142-159.

Papademetri-Kachrimani, C. (2012). Revisiting van Hiele. For the Learning of Mathematics, 32(3), 2-7.

Perry, D. R., \& Steck, A. K. (2015). Increasing student engagement, self-efficacy, and meta-cognitive self-regulation in the high school geometry classroom: do iPads help? Computers in the Schools, 32(2), 122-143.

Perrin-Glorian, M. -J., Mathé, A. -C., \& Leclercq, R. (2013). Comment peut-on penser la continuité de l'enseignement de la géométrie de 6 a 15 ans? Repères-IREM, 90, 5-41.

Pimm, D. (1997). Symbols and meanings in school mathematics. London: Routledge.

Pinxten, R., \& François, K. (2011). Politics in an Indian canyon? Some thoughts on the implications of ethno-mathematics. Educational Studies in Mathematics, 78(2), 261-273.

Pittalis, M., \& Christou, C. (2010). Types of reasoning in 3D geometry thinking and their relation with spatial ability. Educational Studies in Mathematics, 75(2), 191-212.

Popovic, G. (2012). Who is this trapezoid, anyway? Mathematics Teaching in the Middle School, 18(4), 196-199.

Presmeg, N. (2006). Research on visualisation in learning and teaching mathematics. In A. Gutiérrez \& P. Boero (Eds.), Handbook of research on the psychology of mathematics education (pp. 205-304). Rotterdam: Sense Publishers.

Psycharis, G., \& Kynigos, C. (2009). Normalising geometrical figures: dynamic manipulation and construction of meanings for ratio and proportion. Research in Mathematics Education, 11(2), 149-166.

Richard, P. R., Fortuny, J. M., Gagnon, M., Leduc, N., Puertas, E., \& Tessier-Baillargeon, M. (2011). Didactic and theoretical-based perspectives in the experimental development of an intelligent tutorial system for the learning of geometry. ZDM-The Inter-national Journal on Mathematics Education, 43(3), 425-439.

Richter-Gebert, J., \& Kortenkamp, U. H. (2012). The Cinderella.2 manual. Working with the interactive geometry software. Berlin: Springer.

Rivera, F. (2011). Towards a visually-oriented school mathematics classrooms: Research, theory, practice, and issues. New York, NY: Springer.

Rowlands, S. (2010). A pilot study of a cultural-historical approach to teaching geometry. Science and Education, 19(1), 55-73.

Rybak, A., \& Lénárt, I. (2012). Comparative geometry with Geogebra, spherical easel and other didactic tools. GGIJRO, 2(2), 67-76.

Sabena, C. (2008). On the semiotics of gestures. In: L. Radford, G. Schumbring, \& F. Seeger (Eds.), Semiotics in mathematics education: epistemology, history, classroom, and culture (pp. 19-38). Rotterdam: Sense.

Sáenz-Ludlow, A., \& Athanasopoulou, A. (2007). Investigating properties of isosceles trapezoids with the GSP: the case of a pre-service teacher. In D. Pugalee, A. Rogerson, \& A. Schinck (Eds.), Proceedings of the 9th International Conference: Mathematics Education in a Global Community (pp. 577-582). NC: Chapel Hill.

Salinas, T. M., Lynch-Davis, K., Mawhinney, K. J., \& Crocker, D. A. (2014). Exploring quadrilaterals to reveal teachers' use of definitions: results and implications. Australian Senior Mathematics Journal, 28(2), 50-59.

Saltire Software (2016). Geometry Expressions (software package). Sarfaty, Y., \& Patkin, D. (2013). The ability of second graders to identify solids in different positions and to justify their answer. Pythagoras, 34(1), 1-10.

Schellenberg, B. (2010). A proposal for a variation on the axioms of classical geometry. International Journal of Mathematical Education in Science and Technology, 41(3), 311-321.

Schimpf, F., \& Spannagel, C. (2011). Reducing the graphical user interface of a dynamic geometry system. ZDM-The International Journal on Mathematics Education, 43(3), 389-397.

Sears, R., \& Chávez, O. (2014). Opportunities to engage with proof: the nature of proof tasks in two geometry textbooks and its influence on enacted lessons. ZDM-The International Journal on Mathematics Education, 46(5), 767-780.

Sfard, A. (2008). Thinking as communicating: Human development, the growth of discourses, and mathematizing. New York: Cam-bridge University Press.

Shah, P., \& Miyake, A. (2005). The Cambridge handbook of visuospatial thinking. New York: Cambridge University Press.

Shein, P. P. (2012). Seeing with two eyes: a teacher's use of gestures in revoicing to engage English language learners in the repair of mathematical errors. Journal for Research in Mathematics Edu-cation, 43(2), 182-222.

Sinclair, N., \& Bruce, C. (2015). New opportunities in geometry education at the primary school. ZDM Mathematics Education, 51(3), 319-329.

Sinclair, N., \& de Freitas, E. (2014). The haptic nature of gesture: rethinking gesture with multi-touch digital technologies. Gesture, 14(3), 351374.

Sinclair, N., de Freitas, E., \& Ferrara, F. (2012). Virtual encounters: the murky and furtive world of mathematical inventiveness. ZDM-The International Journal on Mathematics Education, 45(2), 239-252.

Sinclair, M., Mamolo, A., \& Whiteley, W. (2011). Designing spatial visual tasks for research: the case of the filling task. Educational Studies in Mathematics, 78, 135-163.

Sinclair, N., \& Moss, J. (2012). The more it changes, the more it becomes the same: the development of the routine of shape identification in dynamic geometry environments. International Journal of Education Research, 51-52, $28-44$.

Sinclair, N., \& Robutti, O. (2013). Technology and the role of proof: the case of dynamic geometry. In Alan Bishop, Ken Clement, Christine 
Keitel, Jeremy Kilpatrick, \& Frederick Leung (Eds.), Third international handbook of mathematics education (pp. 571-596). Berlin: Springer.

Smith, J. T. (2010). Definitions and non-definability in geometry. American Mathematical Monthly, 117(6), 475-489.

Spelke, E. S., Gilmore, C. K., \& McCarthy, S. (2011). Kindergarten children's sensitivity to geometry in maps. Developmental Science, 14(4), 809-821.

Steenpass, A., \& Steinbring, H. (2014). Young students' subjective interpretations of mathematical diagrams: elements of the theoretical construct "frame-based interpreting competence". ZDM-The International Journal on Mathematics Education, 46(1), 3-14.

Stols, G., \& Kriek, J. (2011). Why don't all maths teachers use dynamic geometry software in their classrooms? Australasian Journal of Educational Technology, 27(1), 137-151.

Su, W., Wang, P. S., Cai, C., \& Li, L. (2014). A touch-operation-based dynamic geometry system: design and implementation. In H. Hong \& C. Yap (Eds.), Mathematical software: ICMS 2014 (pp. 235-239). Berlin: Springer.

Tanguay, D., \& Grenier, D. (2010). Experimentation and proof in a solid geometry teaching situation. For the Learning of Mathematics, 30(3), $36-42$.

Tartre, L. (1990). Spatial orientation skill and mathematical problem solving. Journal for Research in Mathematics Education, 21, $216-229$.

Taylor, H., \& Hutton, A. (2013). Think 3d! Training spatial thinking fundamental to STEM education. Cognition and Instruction, 31(4), 434455.

Tessema, K. A. (2007). The teacher education reform process in Ethiopia: some consequences on educators and its implications. Teaching Education, 18(1), 29-48.

Tepylo, D., Moss, J., \& Stephenson, C. (2015). A developmental look at a rigorous block play program. Young Children, 70(1), 18-25.

Thom, J., \& McGarvey, L. (2015). The act and artifact of drawing(s): observing geometric thinking with, in, and through children's drawings. Mathematics Education, 47(3), 465-481.

Trgalova, J., Soury-Lavergne, S., \& Jahn, A. P. (2011). Quality assessment process for dynamic geometry resources in Intergeo project. ZDMThe International Journal on Mathematics Education, 43(3), 337-351.

Usiskin, Z., Griffin, J., Witonsky, D., \& Willmore, E. (2008). The Classification of quadrilaterals: a study of definition. Charlotte: Information Age Publishing.

Uttal, D., Meadow, N. G., Tipton, E., Hand, L. L., Alden, A. R., Warren, C., \& Newcombe, N. S. (2013a). The malleability of spatial skills: a meta-analysis of training studies. Psychological Bulletin, 2, 352-402.

Uttal, D., Miller, D., \& Newcombe, N. (2013b). Exploring and enhancing spatial thinking: links to achievement in science, technology, engineering, and mathematics? Current Directions in Psychological Science, 22(5), 367-373.

Van Hiele, P. M. (1986). Structure and insight: a theory of mathematics education. New York: Academic Press.

Van Putten, S. (2008). Levels of thought in geometry of pre-service mathematics educators according to the van Hiele Model. Unpublished Master's thesis, University of Pretoria.

Venturini, M. (2015). How teachers think about the role of digital technologies in student assessment in mathematics. Unpublished PhD dissertation. Simon Fraser University, Canada.

Verillon, P., \& Rabardel, P. (1995). Cognition and artifacts: a contribution to the study of though in relation to instrumented activity. European Journal of Psychology of Education, 10(1), 77-101.

Vosniadou, S., \& Skopeliti, I. (2014). Conceptual change from the framework theory side of the fence. Science and Education, 23(7), 1427-1445.

Wakwinji, I. (2011). Exploring how a workshop approach helps mathematics teachers start to develop technological pedagogical content knowledge. (Masters), University of Amsterdam.

Walcott, C., Mohr, D., \& Kastberg, S. E. (2009). Making sense of shape: an analysis of children's written responses. Journal of Mathematical Behavior, 28(1), 30-40.

Wang, S., \& Kinzel, M. (2014). How do they know it is a parallelogram? Analysing geometric discourse at van Hiele Level 3. Research in Mathematics Education, 16(3), 288-305.

Watson, A., Jones, K., \& Pratt, D. (2013). Key ideas in teaching mathematics: research-based guidance for ages 9-19. Oxford: Oxford University Press.

Yang, J. C., \& Chen, S. Y. (2010). Effects of gender differences and spatial abilities within a digital pentominoes game. Computers and Education, $55(3), 1220-1233$.

Yang, K.-L., \& Lin, F.-L. (2008). A model of reading comprehension of geometry proof. Educational Studies in Mathematics, 67(1), 59-76.

Yu, P., Barrett, J., \& Presmeg, N. (2009). Prototypes and categorical reasoning. In T. V. Craine (Ed.), Understanding geometry for a changing world, seventy-first yearbook of the National Council of Teachers of Mathematics (NCTM) (pp. 91-108). Reston: NCTM.

Zalamea, F. (2012). Synthetic philosophy of contemporary mathematics. New York: Sequence Press.

Zandieh, M. \& Rasmussen, C. (2010). Defining as a mathematical activity: a framework for characterizing progress from informal to more formal ways of reasoning, Journal of Mathematical Behavior, 29, 55-75. 